\title{
The importance of family background and neighborhood effects as determinants of crime
}

\author{
Karin Hederos Eriksson ${ }^{1}$ - Randi Hjalmarsson ${ }^{2}$. \\ Matthew J. Lindquist ${ }^{1}$ • Anna Sandberg ${ }^{3}$
}

Received: 11 March 2014 / Accepted: 14 July 2015/

Published online: 14 September 2015

(C) The Author(s) 2015. This article is published with open access at Springerlink.com

\begin{abstract}
We quantify the importance of family background and neighborhood effects as determinants of criminal convictions and incarceration by estimating sibling correlations. At the extensive margin, factors common to siblings account for $24 \%$ of the variation in criminal convictions and $39 \%$ of the variation in incarceration. At the intensive margin, these factors typically account for slightly less than half of the variation in prison sentence length and between one third and one half of the variation in criminal convictions, depending on crime type and gender. Further analysis shows that parental criminality and family structure can account for more of the sibling crime correlation than parental income and education or neighborhood characteristics. The lion's share of the sibling correlation, however, is unaccounted for by
\end{abstract}

Responsible editor: Erdal Tekin

Matthew J. Lindquist

matthew.lindquist@sofi.su.se

Karin Hederos Eriksson

karin.hederoseriksson@sofi.su.se

Randi Hjalmarsson

randi.hjalmarsson@economics.gu.se

Anna Sandberg

anna.sandberg@iies.su.se

1 Swedish Institute for Social Research, Stockholm University, SE 10691 Stockholm, Sweden

2 CEPR and Department of Economics, University of Gothenburg, P.O. Box 640, SE 40530

Gothenburg, Sweden

3 Institute for International Economic Studies, Stockholm University, SE 106 91, Stockholm, Sweden 
these factors. Finally, sibling spacing also matters-more closely spaced siblings are more similar in their criminal behavior.

Keywords Crime · Family background · Incarceration · Neighborhood correlation $\cdot$ Prison $\cdot$ Sibling correlation

JEL Classification $\mathrm{J} 13 \cdot \mathrm{J} 62 \cdot \mathrm{K} 42$

\section{Introduction}

There is extensive evidence of similarities in criminal behavior between members of the same family and between households in the same neighborhood. For instance, The Bureau of Justice Statistics reports that approximately $50 \%$ of fathers and mothers in state prison had at least one other family member that had also been incarcerated: $6 \%$ had an incarcerated mother, $19 \%$ had an incarcerated father, $34 \%$ had an incarcerated brother, $7 \%$ had an incarcerated sister, $2 \%$ had an incarcerated child, and $2 \%$ had an incarcerated spouse (Glaze and Maruschak 2008). What is it about these individuals that cause them to engage in similar antisocial behaviors? Answering this question and identifying the relative contribution of different family and community factors to criminal behavior is crucial in our quest to both identify the fundamental causes of criminal behavior and to develop public policies to combat crime.

Thus, the aim of this paper is to contribute to a better understanding of the importance of family background and neighborhood effects as determinants of crime. We do this in two ways. We first quantify the role of family and community background for criminal activity by estimating sibling correlations in criminal convictions and incarceration. Siblings share (among other things) genes, parents, family values, and common influences from peers and neighborhoods. The sibling correlation, therefore, provides us with a broad measure of the importance of family and community factors. It tells us what share of the variation in criminal behavior can be traced back to common influences stemming from family and community background. We then run an accounting exercise to see the extent to which a large set of family-wide variables (parental income and education, parental criminality, family structure, and neighborhoods) can account for the sibling correlations in criminal behavior that we report. While a literature studying sibling correlations in crime certainly exists, as does a literature studying the importance of family and community background effects on crime, ${ }^{1}$ we are aware of little research that has combined these two strands of literature to assess the extent to which various family-wide control variables can account for sibling similarities in crime. ${ }^{2}$

\footnotetext{
${ }^{1}$ From the economics literature see, e.g., Case and Katz (1991), Pezzin (2004), Currie and Tekin (2012), Doyle (2008), Hjalmarsson and Lindquist (2010, 2012, 2013), Akee et al. (2010), and Meghir et al. (2012) for work on family background effects and Case and Katz (1991), Ludwig et al. (2001), Kling et al. (2005), and Damm and Dustmann (2014) for work on neighborhood effects.

${ }^{2}$ Important exceptions include twin studies and the early work of Rowe and Farrington (1997).
} 
Sibling correlations in criminal behavior have been documented in a number of contexts: varying countries, different types of sibling pairs, administrative versus survey data, various crime types, and different measures of criminality. These estimates range from a low of 0.25 (Mazumder 2008) to a high of 0.69 (Johnson 2007). ${ }^{3}$ Twin studies also report strong sibling similarities in antisocial behavior and crime. ${ }^{4}$ Many of these studies, however, use data from small, selected samples, while studies using data from the NLSY or PSID rely on self-reported data covering a limited time period. Frisell et al. (2011) is an important exception. Their study reports (perhaps for the first time) population-wide sibling correlations using police register data in Sweden, albeit only for violent crime at the extensive margin. They find an extensive margin correlation of 0.41 for brothers and 0.48 for sisters.

This paper builds on the existing literature by estimating sibling correlations in criminal convictions and incarceration using Swedish register data on a nationally representative sample of more than 700,000 brothers and sisters born between 1958 and 1968. We have information on all criminal convictions, crime types, and sentences received between the years 1973 and 2007, which allows us to estimate both extensive and intensive margin sibling correlations for different crime types and for both genders.

At the extensive margin, our estimated sibling correlations indicate that factors shared by siblings account for $24 \%$ of the variation in convictions and $39 \%$ of the variation in incarceration. At the intensive margin, we find much larger sibling correlations for higher numbers of crimes and longer prison sentences. For example, the brother correlation in having committed at least one crime is 0.29 , while the brother correlation in having committed at least 10 crimes is 0.51 . We also see similar patterns for sibling correlations after breaking down the data by crime type (violent, property, and other) and no systematic difference between brother correlations and sister correlations. Lastly, we show that closely spaced siblings are more similar in terms of their criminal behavior than are siblings who are born many years apart from each other.

We then go on to study the different factors that could potentially explain why siblings are so similar in terms of their criminal behavior. We first look at the effects of family-wide variables that siblings share: parental income and education, parental criminality, and family structure. These variables have been chosen based on our reading of the previous literature on family background and crime. After including

\footnotetext{
${ }^{3}$ Using data from the Cambridge Study in Delinquent Development, Rowe and Farrington (1997) report sibling correlations in criminal convictions of $0.45-0.50$ for same-sex siblings and 0.27 for opposite-sex siblings. Mazumder (2008) uses data from the NLSY to estimate a sibling correlation in illegal drug use of 0.30 and a brother correlation in incarceration of 0.25 . Using a somewhat different approach, Pezzin (2004) argues that 44-55\% of the total variation in crime among siblings in the NLSY can be attributed to family influences even after controlling for a number of individual and family attributes. Using PSID data, Johnson (2007) reports a brother correlation in having ever been charged or booked with a crime of 0.31 and in incarceration of 0.69 .

${ }^{4}$ See Ishikawa and Raine (2002) and Moffit (2005) for reviews of the behavioral genetics literature concerning antisocial behavior and crime. For an overview of earlier work on sibling similarities in the criminology literature, see Lauritsen (1993).
} 
these potentially important family characteristics as control variables (when estimating the variance components used to construct our sibling correlations), we assess how much of the sibling similarities in criminal behavior they account for. While this decomposition approach has been used to investigate the determinants of sibling similarities in income, health, and education (Mazumder 2008, 2011; Björklund et al. 2010; Anger and Schnitzlein 2013), it has not been applied to criminal behavior.

Sibling correlations decrease by at most $9 \%$ when we control for parental income and education, by at most $21 \%$ when we control for parental criminality, and by at most $19 \%$ when we control for family structure. The largest decrease is seen for the extensive margin measures. Including all of the controls simultaneously decreases the sibling correlations by at most $27 \%$. These results imply that sibling associations in criminal behavior appear to be driven mainly by factors common to siblings other than parental income and education. Parental criminality and family structure appear more important..$^{5}$ But the largest share remains unexplained.

We then show that closely spaced siblings are more similar in terms of their criminal behavior than widely spaced siblings, even after controlling for our full set of family background variables. We argue that part of this effect may be due to a stronger sibling peer effect between closely than widely space siblings. However, using a correlated random-effects model proposed by Altonji et al. (2013), we find little empirical evidence of a direct effect of older siblings' crime on that of their younger sibling in the following period.

We continue our analysis by examining the role of shared neighborhood influences (e.g., schools, peers, local labor markets, etc.) by estimating neighborhood correlations that can (under certain assumptions) be viewed as upper bounds on the potential effects of neighborhood influences (Solon et al. 2000). These correlations tell us that neighborhoods account for only $1 \%$ of the variation in aggregate crime at the extensive margin (or $3 \%$ of sibling similarities) and $2 \%$ of the variation in incarceration at the extensive margin (or $5 \%$ of sibling similarities). At the intensive margin, neighborhood correlations tend to be somewhat larger and explain up to $13 \%$ of the sibling correlation. In a supplementary experiment, we conclude that neighborhood quality may explain part of the neighborhood effect. We also investigate the potential role of family-neighborhood interaction effects.

Together, family-wide variables and neighborhood effects can account for one third of the sibling similarities that we observe in our data, leaving the lion's share unexplained. What these other influences on siblings' behavior might be is discussed in the conclusion. We also discuss several important caveats that must be kept in mind when interpreting the results from our accounting exercise.

\footnotetext{
${ }^{5}$ Since the goal of this paper is to gain a better understanding of what makes siblings so similar in terms of criminal behavior, the metric that we use to measure the "importance" of a control variable is the degree to which it lowers the sibling correlation after being introduced as a control in the fixed part of our mixedeffects model. Our framework allows us to present a structured and informative descriptive analysis of the data in hand. This descriptive analysis does not, however, allow us to judge the relative importance of various causal mechanisms of crime in general.
} 
In the next section, we outline our statistical model and empirical estimation methods. This is followed, in Section 3, by a presentation of our data and descriptive statistics. In Section 4, we present extensive and intensive margin sibling correlations in crime and incarceration. We then proceed in Section 5 to see what share of these correlations can be accounted for by parental income and education, parental criminality, family structure, sibling peer effects, and neighborhood effects. Section 6 concludes.

\section{Statistical model and estimation method}

Criminal behavior, $c_{i f n}$, for sibling $i$ in family $f$ living in neighborhood $n$ can be modeled in a simple linear additive model as

$$
c_{i f n}=\mu+a_{f}+b_{n}+e_{i f n},
$$

where $\mu$ is the population mean, $a_{f}$ is a permanent component common to all siblings in family $f, b_{n}$ is a permanent component common to all children living in neighborhood $n$, and $e_{i f n}$ is unique to individual $i$ in family $f$ from neighborhood $n .^{6}$ The component $e_{i f n}$ captures individual deviations from the family and neighborhood components (including measurement error in our crime variable). If we assume that these components are independent, then the variance of $c_{i f n}$ is the sum of the variances of the family, neighborhood, and individual components:

$$
\sigma_{c}^{2}=\sigma_{a}^{2}+\sigma_{b}^{2}+\sigma_{e}^{2} .
$$

We can also allow families to sort into neighborhoods based on (for example) income and education, which induces a covariance term, $2 \sigma_{a b}^{2}$, so that ${ }^{7}$

$$
\sigma_{c}^{2}=\sigma_{a}^{2}+\sigma_{b}^{2}+2 \sigma_{a b}^{2}+\sigma_{e}^{2} .
$$

The share of the variance in the outcome variable, $c_{i f n}$, which can be attributed to family background and neighborhood effects, is

$$
\rho=\frac{\sigma_{a}^{2}+\sigma_{b}^{2}+2 \sigma_{a b}^{2}}{\sigma_{a}^{2}+\sigma_{b}^{2}+2 \sigma_{a b}^{2}+\sigma_{e}^{2}} .
$$

This share coincides with the correlation in the outcome variable of randomly drawn pairs of siblings, which is why $\rho$ is called a sibling correlation. ${ }^{8}$

A sibling correlation can thus be thought of as an omnibus measure of the impor-

\footnotetext{
${ }^{6}$ We discuss the potential role played by family-neighborhood interaction effects in Section 5.4.

${ }^{7}$ We abstract from the additional complication that measurement error may also be correlated with either family and/or neighborhood effects due to, for example, differential conviction rates by family socioeconomic status or higher policing rates in certain neighborhoods. This type of measurement error would bias our estimated sibling and neighborhood correlations upwards.

${ }^{8}$ Although this common formulation of the sibling correlation is a well-defined statistical entity, it is important to keep in mind that it is still a somewhat arbitrary model of the process that generates sibling similarities. It rules out, for example, the fact that sibling correlations could in theory be negative. Along some dimensions, families may promote inequality.
} 
tance of family background and neighborhood effects. It includes anything shared by siblings: genes, parental income, and parental influences such as aspirations and cultural inheritance, as well as things not directly experienced in the home, such as school, church, and neighborhood effects. If such shared factors are relatively more important than non-shared factors for criminal behavior, the variance of the family effects will be large relative to the variance of the individual effects and the sibling correlation will be high. Thus, the more important the factors that siblings share are, the larger is the sibling correlation. Genetic traits not shared by siblings, differential treatment of siblings, time-dependent changes in neighborhoods, schools, etc. are captured by the individual component $e_{i f n}$. Importantly, the existence of such non-shared factors implies that the sibling correlation should be viewed as a lower bound on the importance of family background and neighborhood effects. 9

In order to calculate the total sibling correlation (including neighborhood effects), $\rho$, we need estimates of the between-family variation, $\sigma_{a}^{2}$, and of the total remaining variation. These can be obtained by estimating the following mixed-effects model:

$$
c_{i f}=\mathbf{x}_{i f} \beta+a_{f}+e_{i f},
$$

where the neighborhood effect, $b_{n}$, is now subsumed by the family effect, $a_{f}$. Gender and birth year dummies are included in $\mathbf{x}_{i f}$.

Since our outcome variables are binary, we reformulate Eq. 5 as a latent linear response model

$$
c_{i f}^{*}=\mathbf{x}_{i f} \beta+a_{f}+e_{i f},
$$

where we only observe $C_{i f}=I\left(C_{i f}^{*}>0\right)$. We estimate Eq. 6 using STATA's $x t$ logit command. The variance components $\sigma_{e}^{2}$ and $\sigma_{a}^{2}$ are estimated using maximum likelihood. The random family effect is estimated conditional on the random individual effect being logistically distributed with mean zero, variance $\sigma_{e}^{2}=\pi^{2} / 3$ and independent of $a_{f}$.

Inspired by the approach used in Mazumder (2008) and Björklund et al. (2010), we then go on to include potentially important family-wide variables, either one at a time or simultaneously, in the $\mathbf{x}_{i f}$ matrix. For example, consider the inclusion of parental income and education in $\mathbf{x}_{i f}$. These additional control variables should reduce the residual variation in the outcome variable and produce a lower estimate of the between-family variation, $\sigma_{a}{ }^{2 *}$, than the estimate produced without the added controls. Abstracting from measurement error, we can interpret the difference between these two estimates, $\sigma_{a}{ }^{2}-\sigma_{a}{ }^{2 *}$, as an upper bound on the amount of the variance in the family component that can be explained by parental income and education. It is viewed as an upper bound since it includes other factors that are correlated with parental income and education. ${ }^{10}$

\footnotetext{
${ }^{9}$ Björklund and Jäntti (2012) discuss this issue in great detail and provide quantitative examples of its importance.

${ }^{10}$ In the presence of measurement error, this difference, $\sigma_{a}^{2}-\sigma_{a}^{2 *}$, is more correctly viewed as a downwardly biased estimate of the upper bound on the amount of the variance in the family component that can be accounted for by parental income and education.
} 
This experiment also produces a new sibling correlation $\rho^{*}$. From what we know about the relationship between parents' income and education and children's crime (see, e.g., Hjalmarsson and Lindquist 2012), we expect this new sibling correlation to be lower but still substantial in magnitude.

The purpose of this accounting exercise is to see which family-wide variables are most important for making siblings similar in terms of their criminal behavior. The metric used in this paper to judge the "importance" of any particular control variable is the degree to which it lowers the sibling correlation after being included as a control in the fixed part of our mixed-effects model. We will use this metric to provide important clues about what is potentially important and unimportant in explaining sibling similarities in crime; this accounting exercise does not, however, allow for a causal interpretation of the determinants of crime. Specifically, we will explore the potential roles played by (i) parental income and education, (ii) parental criminality, and (iii) family structure. The choice of these particular variables is motivated by our reading of the existing literature on family background and crime.

We then go on to explore the potential importance of neighborhood effects for producing sibling similarities. We do this by estimating neighborhood correlations net of sorting into neighborhoods. In the absence of family-neighborhood interaction effects, these act as "tight" upper bounds on the share of the sibling correlation that can be attributed to common neighborhood influences (see Solon et al. 2000).

The share of the variance in the outcome variable, $c_{i f n}$, which can be attributed to neighborhood effects alone (net of sorting), is

$$
\gamma=\frac{\sigma_{b}^{2}}{\sigma_{a}^{2}+\sigma_{b}^{2}+\sigma_{e}^{2}} .
$$

In order to calculate $\gamma$, we need an estimate of the between-neighborhood variation, $\sigma_{b}{ }^{2}$, as well as an estimate of the remaining variation, $\sigma_{a}{ }^{2}+\sigma_{e}{ }^{2}$. These can be obtained by ignoring the between-family variation and estimating the following mixed-effects model

$$
c_{\text {in }}=\mathbf{x}_{\text {in }} \beta+b_{n}+e_{\text {in }} .
$$

Once again, $\mathbf{x}_{i n}$ allows for the inclusion of multiple control variables. Note that the family component, $a_{f}$, is now subsumed by the individual component, $e_{i n}$. To net out sorting into neighborhoods (i.e., to remove the covariance term), we include controls for parents' income, education and criminality, and family structure in $\mathbf{x}_{i n} \cdot{ }^{11} \mathrm{We}$ also include gender and birth year dummies. ${ }^{12}$

\footnotetext{
${ }^{11}$ Sorting on unobservables may also occur. To the extent that these unobservable characteristics are uncorrelated with our control variables, they will bias our estimated neighborhood correlations upwards.

${ }^{12}$ In practice, we estimate neighborhood correlations after first randomly drawing one child from each family. We do this, so that large families living in small neighborhoods will not dominate the estimation. Alternatively, one could estimate neighborhood, family, and individual variance components simultaneously by applying STATA's xtmelogit to the whole sample and estimating a model with three levels. But due to our large sample, our use of control variables, and the large number of correlations that we need to calculate in this paper, this approach becomes infeasible; running time and convergence become problematic. In some cases, we have used both methods and the answer does not change. The fact that we randomly sample one child from each family does not seem to matter much either.
} 


\section{Data and descriptive statistics}

\subsection{Data}

The sample used in this paper was created in the following manner. We start with a $25 \%$ random sample from Sweden's Multigenerational Register, which includes all persons born from 1932 onwards who have lived in Sweden at any time since 1961. We then match on all of their brothers and sisters. This matching is made possible by the fact that all family ties (biological and adoptive) are recorded in Sweden's Multigenerational Register. ${ }^{13}$ Those who died or emigrated from Sweden before their 16th birthday are dropped from the sample. We also remove those who immigrated to Sweden after their 25th birthday.

Siblings are defined as those having the same biological or adoptive mother. Among non-singletons, $98 \%$ have at least one full sibling in the sample (i.e., $2 \%$ of the non-singletons have a maternal half sibling but no full sibling). ${ }^{14}$

Our sibling sample was then matched with Sweden's official crime register. This matching is made possible by the unique personal identification number that each Swedish resident possesses. Our data include a full record of criminal convictions for the years 1973 to 2007 for each individual in the data set. Records include crime type and sanctions received.

Given the years for which crime data are available, we choose to restrict our sample to siblings born between 1958 and 1968. This means that siblings are born at most ten calendar years apart. These age restrictions also imply that we have 35 years of crime data for our oldest cohort (born 1958) and that the crime data for this cohort span the ages of 15 to 49 . For the youngest cohort (born 1968), we will use 25 years of crime data that span the ages 15 to 39 . The age of criminal majority in Sweden is 15 .

We use our crime data to construct a number of different crime variables. The first variable, Crime, is a measure of crime at the extensive margin. That is, it is equal to one if a person has ever been convicted of a crime between 1973 and 2007 and zero if he has not. The next three variables consider the types of crimes committed: violent, property, and other. We create variables indicating whether a person has been convicted of each of these three types of crimes between 1973 and 2007. ${ }^{15}$ We also create an intensive margin measure of aggregate crime that we

\footnotetext{
${ }^{13}$ Very few children in these cohorts lived with pure social siblings, i.e., together with other children that they had no blood relationship with.

${ }^{14}$ We drop all observations with missing mothers from the analysis. In total, 26,907 observations have missing mothers; $96 \%$ of these observations are immigrants. Among the dropped observations, $25 \%$ have been convicted of a crime as compared to $29 \%$ of the observations kept in the sample.

${ }^{15}$ Violent crimes, or crimes against persons, are crimes covered by chapters 3-7 in the Swedish criminal code (brottsbalken). Property crimes are those included in chapters 8-12 in the criminal code. These are standard definitions used by Sweden's National Council for Crime Prevention. All remaining crimes
} 
label Number of Crimes. This variable is the total number of crimes that a person has been convicted of. This variable is also broken down by crime type: violent, property, and other.

One conviction may include several crimes. Our crime type variables are created by looking over all of the crimes within every conviction. ${ }^{16}$ Speeding tickets, parking tickets, and other forms of minor disturbances (ticketable offenses) are not included in our crime measure. It must be an offense that is serious enough to be taken up in court and that results in an admission of guilt or a guilty verdict.

We create variables for the extensive and intensive margins for incarceration. The variable Prison is equal to one if the individual has ever been sentenced to prison and zero otherwise, and Days Sentenced to Prison tells us the total number of days an individual has been sentenced to prison between 1973 and 2007. This variable is summed across all prison sentences if the person has received more than one prison sentence during this time period. However, one should keep in mind that even the extensive margin Prison variable tells us about the intensity of one's criminal career, as one is only eligible for prison if the intensity of the convicted offense(s) is great enough (in terms of offense severity or quantity) or the criminal history is severe enough.

The crime variables described above are also created for the parents of our sample of siblings. The main difference is that parents are much older when we observe them in our crime data. We also have data on parental education and income, as well as family structure when our siblings are young. Siblings can be placed into the neighborhoods they were raised in as children based on their parish of residence. More detailed information concerning parent and neighborhood variables are presented in Sections 5.

\subsection{Descriptive statistics}

Table 1 shows the number of families having $N$ children and Table 2 presents descriptive statistics. Our final sample consists of 707,613 individuals (363,234 men and 344,379 women) from 414,697 families. The mean number of siblings in each family is 1.7 . In our sample, $29 \%$ of the individuals are singletons (i.e., they have no

\footnotetext{
are labeled as "other." The five most common violent crimes are (in order of frequency) assault, molestation, unlawful threat, aggravated assault, and aggravated unlawful threat. The five most common property crimes are petty theft (mainly shoplifting), theft, vandalism, larceny, and fraud. The five most common "other" crimes are dangerous driving, driving without a license, unlawful driving, smuggling, and minor narcotic offenses.

${ }^{16}$ Thus, if you steal a car, then commit an armed robbery and then get caught after a high-speed chase, you will have one trial and one sentence that include convictions for at least three crime types. In this case, the individual would receive violent $=1$ (armed robbery), property $=1$ (car theft), and other $=1$ (serious traffic offense + resisting arrest)
} 
Table 1 Number of families with $N$ children

\begin{tabular}{lll}
\hline$N$ children & Nr of families & Nr of individuals \\
\hline 1 & 206,901 & 206,901 \\
2 & 144,096 & 288,192 \\
3 & 47,872 & 143,616 \\
4 & 11,798 & 47,192 \\
5 & 2909 & 14,545 \\
6 & 804 & 4824 \\
7 & 228 & 1596 \\
8 & 68 & 544 \\
9 & 15 & 135 \\
10 & 3 & 30 \\
11 & 1 & 11 \\
12 & 1 & 12 \\
15 & 1 & 15 \\
Total & 414,697 & 707,613 \\
\hline
\end{tabular}

All children of the same mother are defined as belonging to the same family

siblings in the sample). We include singletons to increase the precision of the estimate of the between-family variation, though our results are not sensitive to their inclusion/exclusion.

Turning to the measures of criminal behavior, $28.5 \%$ of the sample individuals have been convicted of a crime. Criminal convictions are 3.5 times more common among men than women; $43.7 \%$ of men and $12.5 \%$ of women have been convicted of a crime. For both men and women, violent crimes are least frequent while other crimes are most frequent. Only $5.5 \%$ of the individuals have been convicted of a violent crime, while $13.7 \%$ have been convicted of a property crime and $22.5 \%$ of some other crime. ${ }^{17}$

Among the individuals convicted of a crime, the average number of crimes is 6.8 . This number is 7.7 for men and 3.8 for women. Among the individuals convicted of a violent crime, the average number of violent crimes is 2.7 . The corresponding number is 4.4 for other crimes and 5.9 for property crimes. Thus, given that an individual has been convicted of a crime of a specific type, the intensive margin frequency of that crime type is highest for property crimes and lowest for violent crimes. This pattern applies to both men and women. $4.4 \%$ of the individuals have been sentenced to prison. Prison sentences are 11.1 times more common among men than among women; $7.8 \%$ of the men compared to only $0.7 \%$ of the women have been sentenced

\footnotetext{
${ }^{17}$ While some of these statistics may seem high, it is important to note that they are (i) comparable to other studies of crime in Sweden (see for instance Hjalmarsson and Lindquist (forthcoming) and Meghir et al. 2012) and (ii) largely driven by the other crime category, which includes a number of alcohol-related offenses.
} 
to prison. For an individual sentenced to prison, the average prison sentence (summed over all prison sentences) is 455 days, 463 days for men and 367 for women. The median is 91 days ( 3 months) for both men and women.

\section{Sibling correlations in criminal convictions and incarcerations}

\subsection{Extensive margin}

We report the extensive margin sibling correlations in Table $3 .{ }^{18}$ The overall pooled correlation in crime is 0.24 , suggesting that about one fourth of the variation in crime at the extensive margin can be attributed to factors shared by siblings. The sister correlation is 0.24 and the brother correlation is 0.29 . The correlation for mixed siblings is $0.23 .^{19}$

Throughout Table 3, the correlation for mixed siblings is always somewhat less than the sibling correlations reported for brothers and/or sisters. This suggests that siblings of different genders have fewer shared family or community factors; this could be driven by a number of explanations, including that parents treat sons and daughters differently, males and females have different peer groups and school experiences, and males and females are simply differentially affected by the same family characteristics. It could also be that sibling peer effects are stronger for same-sex siblings.

Investigating one crime type at a time, the sibling correlation is 0.33 for property crime, 0.35 for violent crime, and 0.21 for other crime. For prison, the correlation is 0.39 . The correlation for all siblings is thus substantially higher for property crimes and violent crimes than for other crimes, and higher for prison than for all crime outcomes. That is, shared family and community factors appear to explain more of the variation in serious crime than minor crime. This pattern also applies to the brother and sister correlations. The brother correlations are slightly higher than the sister correlations for crime $(0.29$ versus 0.24$)$, property crime $(0.38$ versus 0.34$)$, and other crime (0.24 versus 0.21$)$. For violent crime, the brother and sister correlations are the same (0.37), and for prison, the brother correlation is lower than the sister correlation $(0.39$ versus 0.44$)$. The sister correlation in prison, which is the highest of all extensive margin sibling correlations, suggests that $44 \%$ of the variation in female incarceration at the extensive margin can be accounted for by family and community factors shared by sisters. ${ }^{20}$

\footnotetext{
${ }^{18}$ These correlations are estimated using STATA's xtlogit command. The outcome variables are always dichotomous. Year and gender dummies are included in these estimations. Singletons are included, except when estimating the sibling correlations for mixed siblings. The estimated correlations are never sensitive to the inclusion/exclusion of singletons.

${ }^{19}$ Mixed siblings are defined as follows. In a group of siblings of size $N \geq 2, x \geq 1$ siblings do not have the same gender as the other $N-x$ siblings. Singletons are, therefore, always excluded.

${ }^{20}$ Finally, we note that when looking at sibling correlations for different birth cohorts, there is no notable trend in the correlations over time. This is true when controls are included and excluded and when looking at neighborhood correlations as well.
} 
Table 2 Descriptive statistics

\begin{tabular}{|c|c|c|c|}
\hline & All & Men & Women \\
\hline Number of observations & $\begin{array}{l}707,613 \\
(100 \%)\end{array}$ & $\begin{array}{l}363,234 \\
(51.33 \%)\end{array}$ & $\begin{array}{l}344,379 \\
(48.67 \%)\end{array}$ \\
\hline Year of birth & $\begin{array}{l}1963.1 \\
(3.130)\end{array}$ & $\begin{array}{l}1963.1 \\
(3.130)\end{array}$ & $\begin{array}{l}1963.1 \\
(3.130)\end{array}$ \\
\hline Crime & $\begin{array}{l}0.285 \\
(0.452)\end{array}$ & $\begin{array}{l}0.437 \\
(0.496)\end{array}$ & $\begin{array}{l}0.125 \\
(0.331)\end{array}$ \\
\hline Property crime & $\begin{array}{l}0.137 \\
(0.344)\end{array}$ & $\begin{array}{l}0.207 \\
(0.405)\end{array}$ & $\begin{array}{l}0.064 \\
(0.245)\end{array}$ \\
\hline Violent crime & $\begin{array}{l}0.055 \\
(0.228)\end{array}$ & $\begin{array}{l}0.095 \\
(0.294)\end{array}$ & $\begin{array}{l}0.012 \\
(0.109)\end{array}$ \\
\hline Other crime & $\begin{array}{l}0.225 \\
(0.418)\end{array}$ & $\begin{array}{l}0.363 \\
(0.481)\end{array}$ & $\begin{array}{l}0.079 \\
(0.270)\end{array}$ \\
\hline $\mathrm{Nr}$ of crimes $\mid \mathrm{Nr}$ of crimes $>0$ & $\begin{array}{l}6.825 \\
(21.248)\end{array}$ & $\begin{array}{l}7.655 \\
(23.118)\end{array}$ & $\begin{array}{l}3.764 \\
(11.543)\end{array}$ \\
\hline $\mathrm{Nr}$ of property crimes $\mid \mathrm{Nr}$ of property crimes $>0$ & $\begin{array}{l}5.944 \\
(14.926)\end{array}$ & $\begin{array}{l}6.661 \\
(16.403)\end{array}$ & $\begin{array}{l}3.514 \\
(7.633)\end{array}$ \\
\hline $\mathrm{Nr}$ of violent crimes $\mid \mathrm{Nr}$ of violent crimes $>0$ & $\begin{array}{l}2.663 \\
(3.549)\end{array}$ & $\begin{array}{l}2.779 \\
(3.683)\end{array}$ & $\begin{array}{l}1.688 \\
(1.841)\end{array}$ \\
\hline $\mathrm{Nr}$ of other crimes $\mid \mathrm{Nr}$ of other crimes $>0$ & $\begin{array}{l}4.372 \\
(12.465)\end{array}$ & $\begin{array}{l}4.691 \\
(13.110)\end{array}$ & $\begin{array}{l}2.826 \\
(8.518)\end{array}$ \\
\hline Prison & $\begin{array}{l}0.044 \\
(0.204)\end{array}$ & $\begin{array}{l}0.078 \\
(0.269)\end{array}$ & $\begin{array}{l}0.007 \\
(0.083)\end{array}$ \\
\hline Prison $\mid \mathrm{Nr}$ of crimes $>0$ & $\begin{array}{l}0.153 \\
(0.360)\end{array}$ & $\begin{array}{l}0.179 \\
(0.384)\end{array}$ & $\begin{array}{l}0.055 \\
(0.229)\end{array}$ \\
\hline Days sentenced to prison|days sentenced to prison $>0$ & $\begin{array}{l}455.258 \\
(927.970)\end{array}$ & $\begin{array}{l}462.639 \\
(947.832)\end{array}$ & $\begin{array}{l}367.062 \\
(638.470)\end{array}$ \\
\hline
\end{tabular}

Standard deviations (or \%) in parentheses

\subsection{Intensive margin}

The intensive margin correlations are computed using binary outcome variables. ${ }^{21}$ For crime, we have constructed binary outcome variables taking the value 1 if an individual has committed at least $x$ crimes (where $x$ is equal to $1,2,3,4,5$, or 10 crimes). For prison sentence length, we have constructed binary outcome variables indicating if an individual has spent a total of at least $x$ months in prison (where $x$ is

\footnotetext{
${ }^{21}$ These correlations are estimated using STATA's xtlogit command. Year and gender dummies are included in these estimations. Singletons are included, except when estimating the sibling correlations for mixed siblings. The estimated correlations are never sensitive to the inclusion/exclusion of singletons.
} 
Table 3 Extensive margin sibling correlations

\begin{tabular}{lllll}
\hline & All siblings & Brothers & Sisters & Mixed siblings \\
\hline \multirow{2}{*}{ Crime } & 0.244 & 0.287 & 0.242 & 0.228 \\
& $(0.003)$ & $(0.005)$ & $(0.007)$ & $(0.004)$ \\
Property crime & 0.331 & 0.375 & 0.335 & 0.308 \\
& $(0.004)$ & $(0.005)$ & $(0.009)$ & $(0.005)$ \\
Violent crime & 0.348 & 0.371 & 0.374 & 0.315 \\
& $(0.006)$ & $(0.007)$ & $(0.021)$ & $(0.007)$ \\
Other crime & 0.213 & 0.243 & 0.209 & 0.196 \\
& $(0.003)$ & $(0.005)$ & $(0.009)$ & $(0.004)$ \\
Prison & 0.387 & 0.386 & 0.435 & 0.364 \\
\multirow{2}{*}{ Nr of observations } & $(0.006)$ & $(0.007)$ & $(0.026)$ & $(0.008)$ \\
\hline
\end{tabular}

Sibling correlations are estimated using STATA's xtlogit command. All outcome variables are dichotomous. Birth year and gender dummies are included. Standard errors are in parentheses. Singletons are included, except in the estimation of the mixed siblings. Estimates are not sensitive to the inclusion/exclusion of singletons

equal to $0.5,1,2,3,4,5,6$, or 12 months). We show the intensive margin correlations in Fig. 1 along with approximate $95 \%$ confidence intervals.

The trend line in Fig. 1 is upward sloping for sibling correlations in crime. This means that factors shared by siblings account for a larger share of the variation in crime at the intensive margin. For instance, for sisters, the share of the variation that can be attributed to factors shared by siblings is more than twice as high for "at least 10 crimes" than for "at least 1 crime."

This upward-sloping trend line is present across all different crime types (see Appendix Fig. 7) and is quite similar for both brothers and sisters. The intensive margin correlations for mixed siblings, however, are noticeably lower than those for same-sex siblings, though the same upward trend in the correlation persists. For prison sentence length, there is a weakly upward-sloping trend for brothers but not for sisters; it should be noted, however, that the sister correlations are relatively imprecise due to the low rate of female incarceration.

Taken together, the sibling correlations presented above suggest that family background is a stronger determinant of crime at the intensive margin than it is at the extensive margin. It is responsible for between 33 and $57 \%$ of the variation in crime at the intensive margin, depending on crime type, the number of crimes committed, and gender. This conclusion is also supported by the findings that (i) the extensive margin correlations for property and violent crimes, which tend to contain more relatively serious offenses, were greater than those for other crimes and (ii) the extensive margin incarceration correlation was stronger than that for convictions, as having any incarceration spells can be seen as a proxy for the severity of criminality since more severe crimes or more convictions (concurrently or in the past) are more likely to result in an incarceration spell. 


\section{Crime}

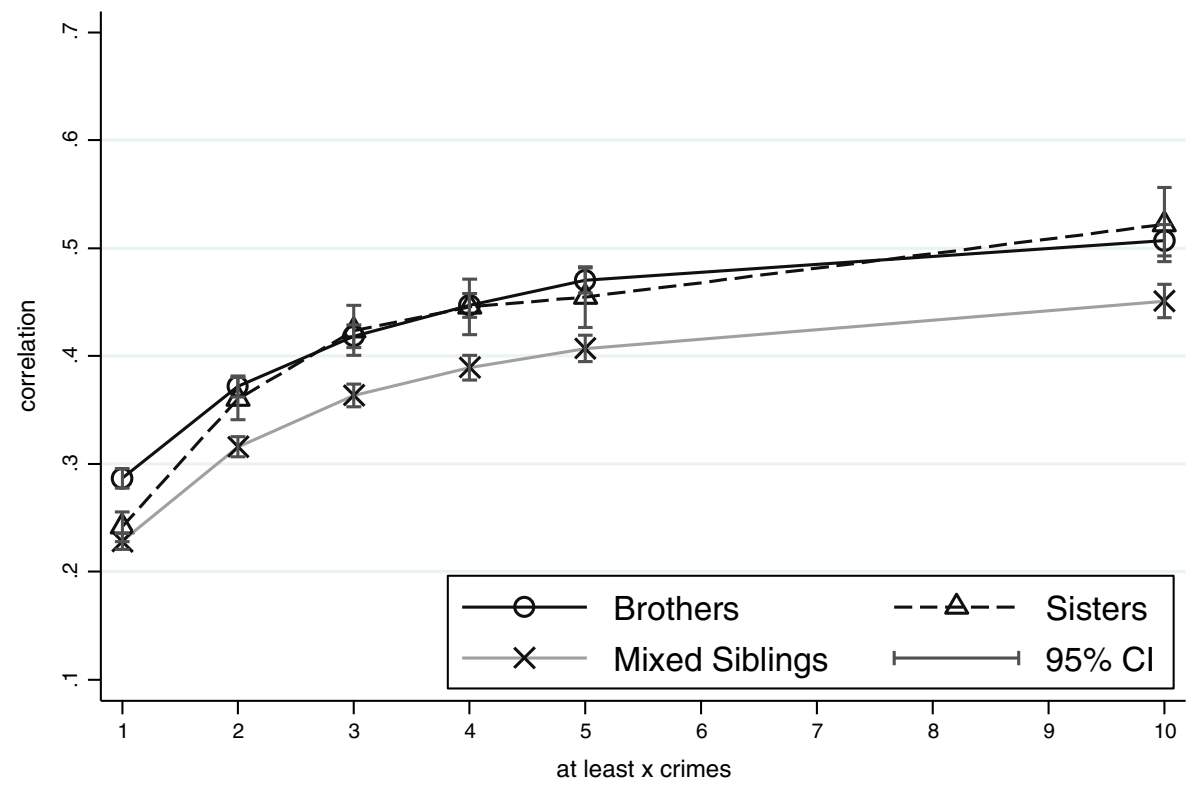

Prison

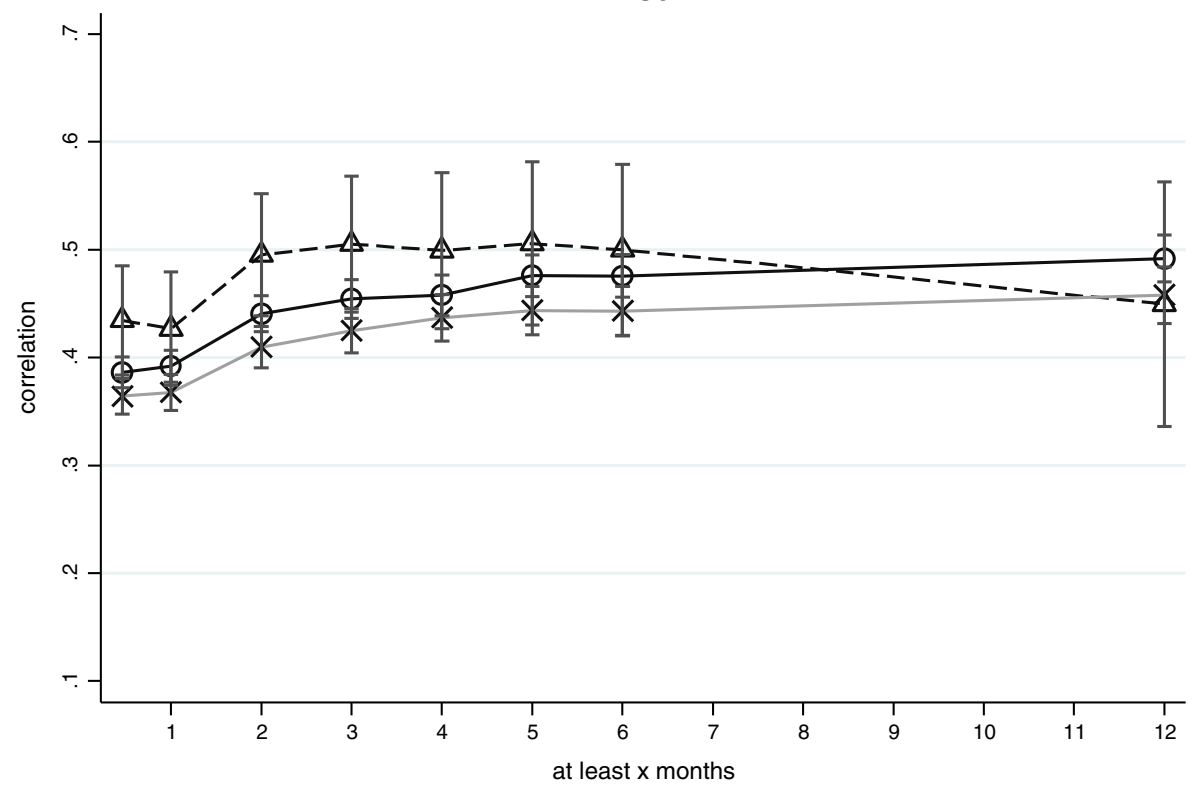

Fig. 1 Sibling correlations in crime and prison 
Thus, while family and community background are important determinants of whether an individual begins a criminal career, they appear to be even more important determinants of the intensity (severity and length) of that criminal career. This naturally leads to the question of why? One possible explanation is social interactions or peer effects within a family: each sibling's criminal behavior reinforces the criminal behavior of the other. ${ }^{22}$ Alternatively, different risk factors may cluster within families or be strongly correlated over time. Parental attitudes, parenting strategies, and family resources (broadly defined) may also affect how successful parents are at correcting episodes of deviant behavior that many teenagers experience.

\subsection{Sibling spacing}

In our baseline sample, siblings can be born up to 10 years apart from each other. In Fig. 2, we report estimates of the brother and sister correlation in crime between pairs of brothers and sisters born (i) at most 4 years apart, (ii) 4 to 6 years apart, (iii) 6 to 8 years apart, and (iv) 8 to 10 years apart. At the extensive margin, we see that the share of the variation in crime explained by common family background is similar for those born within 4 years of each other and those born 4 to 6 years apart; given that a majority of siblings in the sample are within 6 years of each other, these estimates also correspond to our baseline estimates for the full sample. In contrast, the share of variation in crime explained by common family background is lower for those born more than 6 years apart. This is particularly true for sisters born more than 8 years apart. $^{23}$ Two patterns emerge at the intensive margin. First, for all siblings, regardless of how far apart they are in age, the same upward trend in the correlation is seen as the number of crimes studied increases. Second, the intensive margin correlations monotonically decreases as the sibling spacing increases: this is true regardless of which intensive margin is being studied (i.e., at least two offenses, at least three offenses, etc.).

So why might sibling spacing matter for the size of the sibling correlation? We believe that there are two main reasons for this. First, siblings born further apart may, in fact, not experience the same types of environments while growing up. This can be true even if siblings grow up with their biological parents in an intact family, as, for instance, they may experience the same factor (e.g., parental earnings) at different ages and corresponding periods in their development. Second, it

\footnotetext{
${ }^{22}$ See Altonji et al. (2013) for a study of sibling peer effects in substance abuse, Bayer et al. (2008) for evidence of similar reinforcing peer effects in juvenile correctional facilities, and Lindquist and Zenou (2014) for a study on peer effects in networks of co-offenders.

${ }^{23}$ One should keep in mind that sibling pairs born many years apart comprise only a small fraction of the baseline sample. The standard errors on these estimates are also very large.
} 

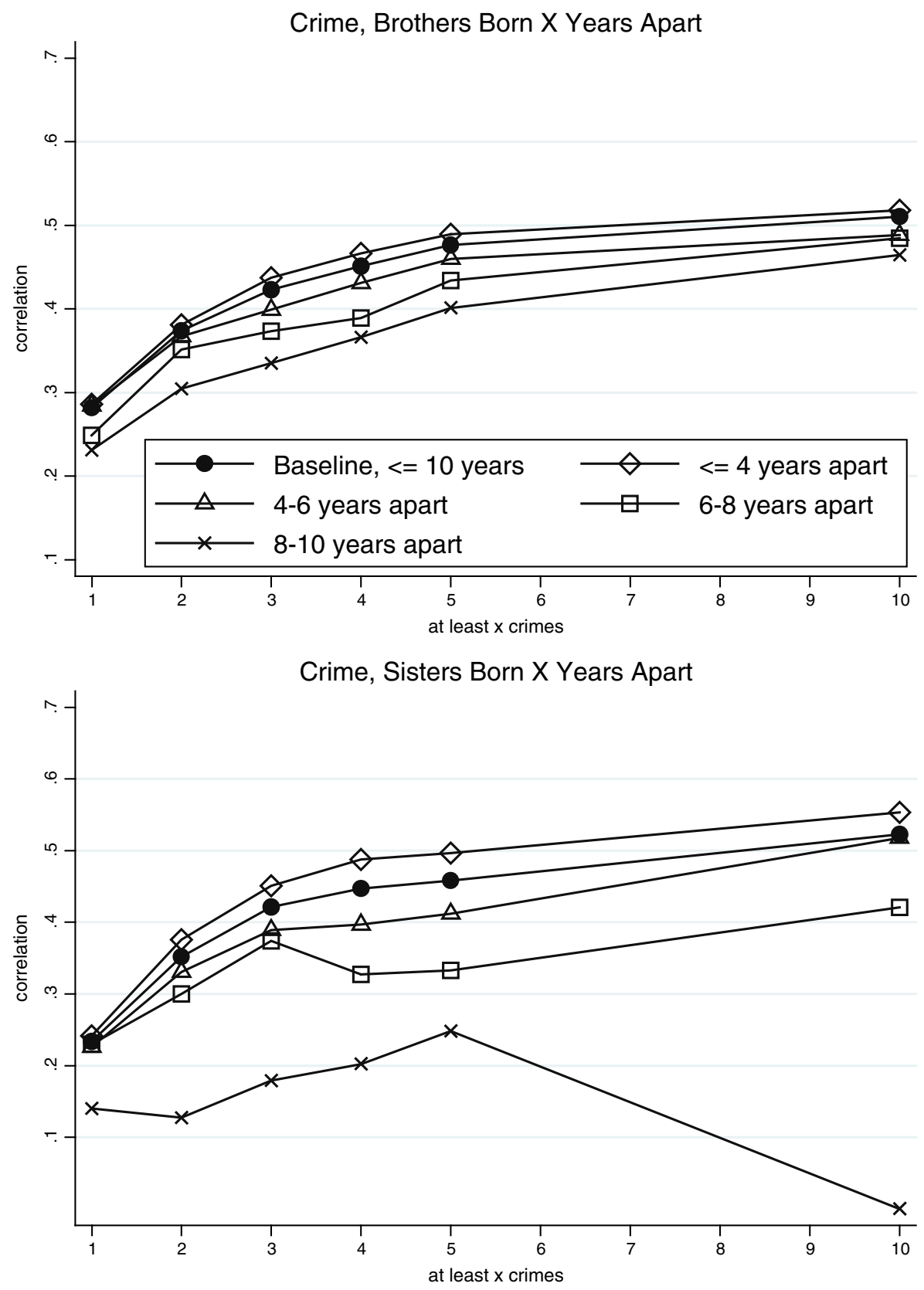

Fig. 2 Sibling correlations in crime for brother and sister pairs born $X$ years apart

may be the case that siblings born close together have a stronger influence on each other's behavior. That is, closely spaced siblings may experience stronger sibling peer effects. Regardless of the mechanism, we need to consider sibling spacing when 
accounting for the size of the sibling correlation. We return to this discussion in Section 5.2 below.

\section{Accounting for sibling correlations in criminal convictions and incarcerations}

\subsection{The role of parental education, income, and crime and family structure}

Can family-wide factors explain sibling similarities in crime? In this section, we present the results of our accounting exercise, which explores a number of characteristics that are common to individuals within the same family, but which vary across families, to gauge the extent to which these factors contribute to the high sibling correlation in crime. In particular, we consider parental education and income, parental criminality, and family structure.

We choose these particular variables because of the existing literature demonstrating their relative importance in explaining crime. For instance, an individual's education has been demonstrated to have a causal impact on his own criminal behavior (Lochner and Moretti 2004; Machin et al. 2011; Hjalmarsson et al. forthcoming) and has even been demonstrated to have an impact on the next generation's criminal behavior (Meghir et al. 2012). These facts, combined with the evidence on the intergenerational transmission of education (see, e.g., Holmlund et al. 2011), suggest that parental education may explain a substantial share of sibling crime correlations. Similar findings have been found for parental income. Akee et al. (2010) demonstrate that parental income has a causal impact that lowers the probability of minor offenses among children and the likelihood that a child self-reports that he/she has sold drugs.

There is also evidence that parental criminality is a strong predictor of child criminality; for example, Hjalmarsson and Lindquist (2013) find that having a father (mother) with at least one conviction increases the son's chance of conviction by 12.1 (13.4) percentage points, respectively. ${ }^{24}$ Finally, there is an extensive sociology literature demonstrating the positive relationship between family structure (e.g., teenage mothers, female-headed households, or single-parent households) and children's criminal behavior, though it is often hard to distinguish correlation from causality. ${ }^{25}$

As discussed in Section 3, our measures of parent criminality and incarceration are constructed in the same manner as those for siblings. Mothers' and fathers' educations are measured in seven levels ranging from grade school to graduate school. These levels are included separately for each parent as dummies in our regressions. We also include a dummy for missing education. Parental income is measured as the

\footnotetext{
${ }^{24}$ In addition, Hjalmarsson and Lindquist (2012) find that sons whose fathers have at least one sentence have 2.06 times higher odds of having at least one criminal conviction than sons whose fathers do not have any sentence.

${ }^{25}$ Cáceres-Delpiano and Giolito (2012) provide recent evidence of a causal relationship, as they demonstrate that the change in US divorce laws to unilateral divorce (i.e., making divorce easier) increased violent crime rates by almost $9 \%$.
} 
log of average real income for the years 1968-2007 (zeros are averaged in, while the very few missing observations are left out). Once again, this is entered separately for each parent.

We have created several different measures of family structure, and we always include all of them simultaneously. First, we have a measure of household size for when the child was age 15 . Second, we include a dummy if the father is unknown. Third, we include the mother's age at the birth of her first child. Lastly, we include a measure of household type at age 15, which includes six categories: (i) unknown, (ii) single mom, (iii) single dad, (iv) both parents living together, (v) mother and new father, and (vi) father and new mother.

We show the sibling correlations estimated with and without controls for up to 10 crimes in Fig. 3 and for up to 1 year in prison in Fig. 4. In Appendix Figs. 9, 10, and 11 , we show the results broken down by crime type. Note that these three categories of controls (i.e., parental income/education, parental criminality, and family structure) are first entered separately in the model and then, in a final specification, simultaneously. When discussing the results of these specifications, we refer to the degree to which the sibling correlation is lowered when adding the various controls; this is our metric for measuring the "importance" of a control variable. ${ }^{26}$

When we control for both parental income and education at the same time, the brother correlations decrease by at most $9 \%$ (for "at least one violent crime") and the sister correlations decrease by at most $8 \%$ (for "at least two crimes"). The brother correlations in prison sentence length decrease by at most $9 \%$ (for "at least 2 weeks in prison"), while none of the decreases in the sister correlations in prison sentence length are statistically significant.

Compared to the baseline correlations with no controls, controlling for just parental criminality decreases the correlations in criminal convictions by at most $13 \%$ for brothers (for "at least one other crime") and $17 \%$ for sisters (for "at least one other crime"). The correlations in prison sentence length decrease by at most $11 \%$ for brothers (for "at least 2 weeks in prison") and $21 \%$ for sisters (for "at least 1 month in prison"). In general, the percentage decreases are larger for sisters than for brothers.

Are these results in line with what one might expect given the results reported in the literature on intergenerational crime? Hjalmarsson and Lindquist (2013) report a father-offspring association of 0.121 and a mother-offspring association of 0.134 for having at least one conviction of any type. Squaring these numbers (i.e., applying Solon's (1999) decomposition formula) and then dividing by the sibling correlation tells us that parental criminality (and its correlates) should account for between 6 and $7 \%$ of the sibling correlation if only one parent has a conviction. ${ }^{27}$ If both parents are convicted, then the parent-offspring association is 0.228 (Hjalmarsson and Lindquist 2013 ) and can account for $21 \%$ of the sibling correlation in crime. ${ }^{28}$ Thus, our new

\footnotetext{
26"Importance" refers to the ability of the control variable to explain the sibling correlation in crime, not the ability of the variable to explain crime more generally.

${ }^{27} 0.121^{2} / 0.244=0.060,0.134^{2} / 0.244=0.074$.

${ }^{28} 0.228^{2} / 0.244=0.213$.
} 
Brother correlations in Crime Controlling for Parental Income and Education

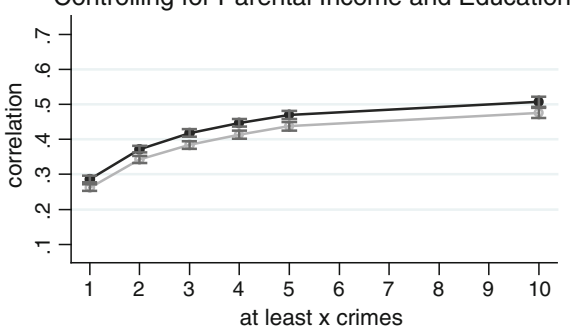

Brother correlations in Crime

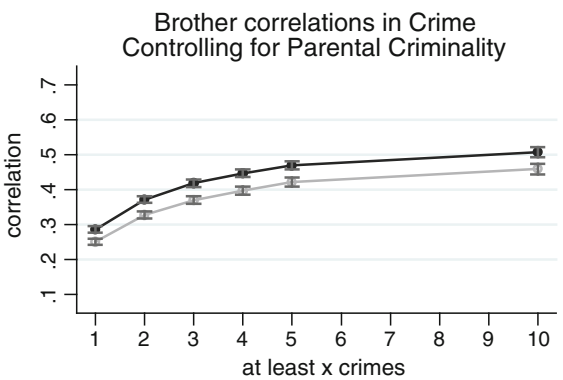

Brother correlations in Crime Controlling for Family Structure

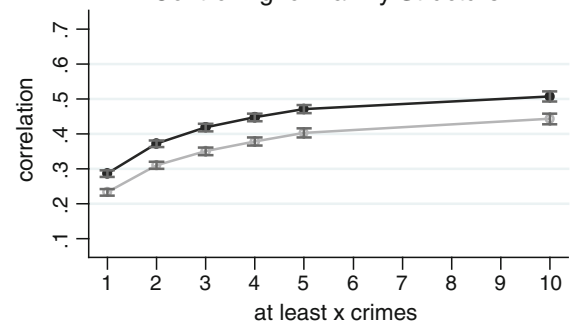

Brother correlations in Crime Controlling for All Family Background Variables

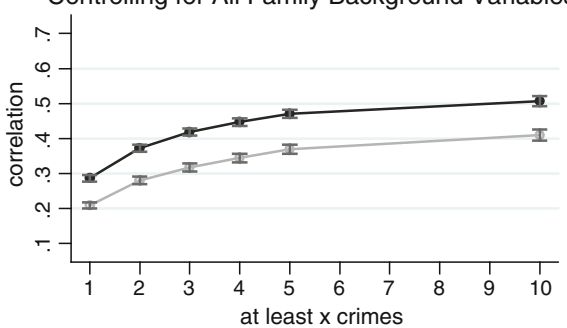

Sister correlations in Crime

Controlling for Parental Income and Education

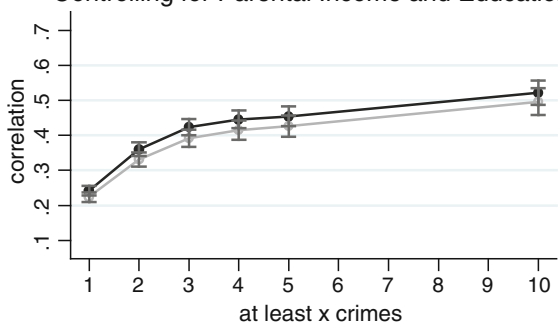

Sister correlations in Crime Controlling for Parental Criminality

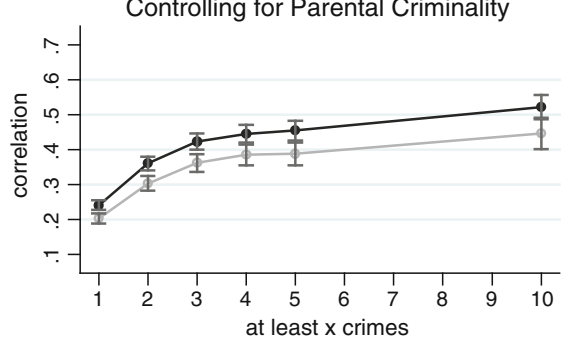

Sister correlations in Crime Controlling for Family Structure

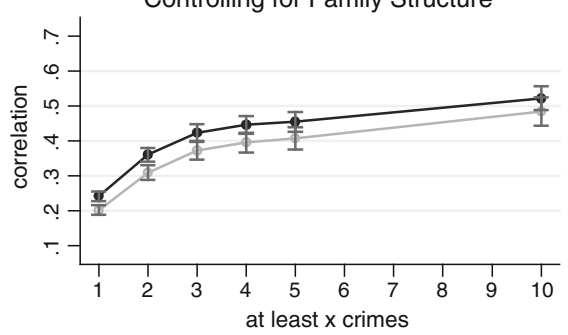

Sister correlations in Crime

Controlling for All Family Background Variables

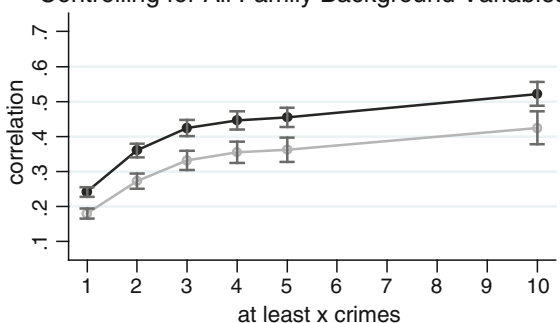

Fig. 3 Sibling correlations in crime controlling for parental income and education, parental criminality, and family structure. Note: We show the sibling correlations estimated with (without) controls in grey (black)

findings appear to be in line with what one might expect from the results reported in the intergenerational crime literature.

Despite this, we are still concerned that we might be underestimating the impor- 
Brother correlations in prison sentence Controlling for Parental Income and Education

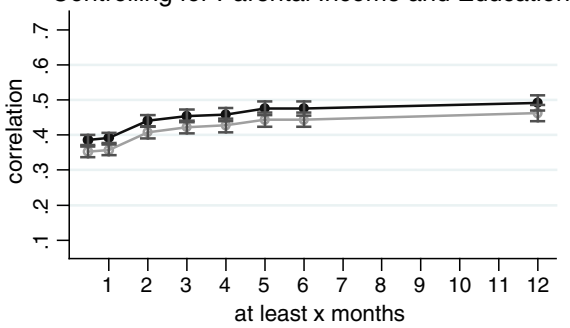

Brother correlations in prison sentence Controlling for Parental Criminality

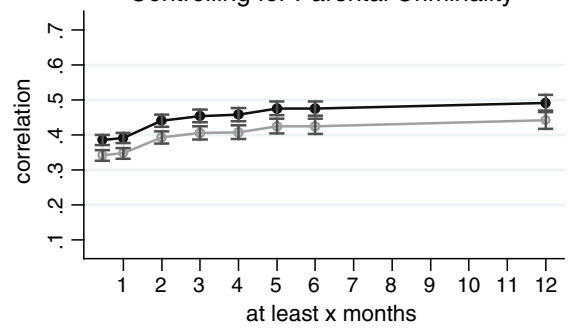

Brother correlations in prison sentence Controlling for Family Structure

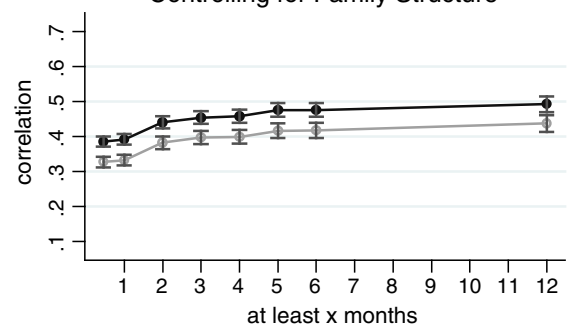

Brother correlations in prison sentence Controlling for All Family Background Variables

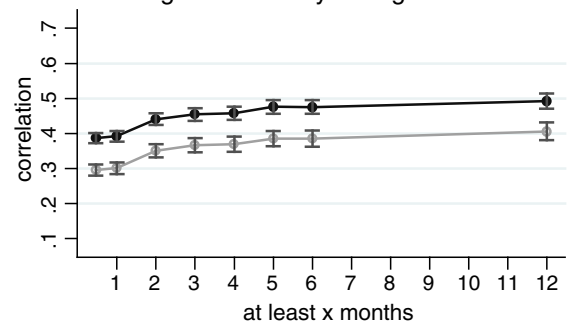

Sister correlations in prison sentence Controlling for Parental Income and Education

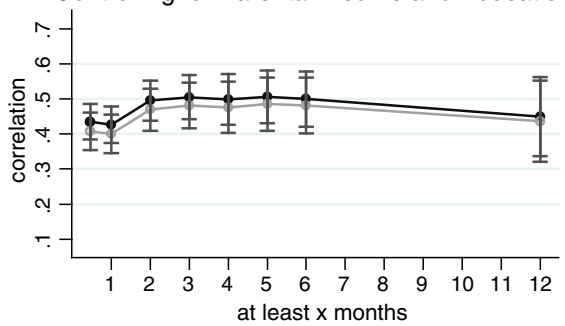

Sister correlations in prison sentence

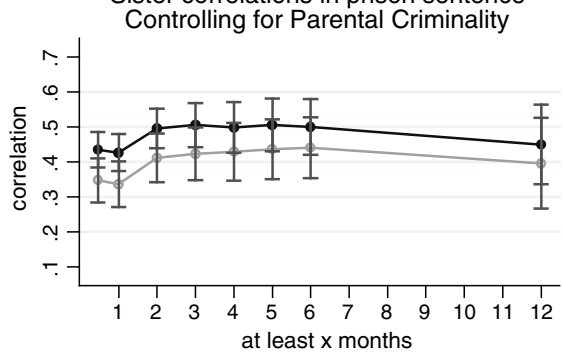

Sister correlations in prison sentence Controlling for Family Structure

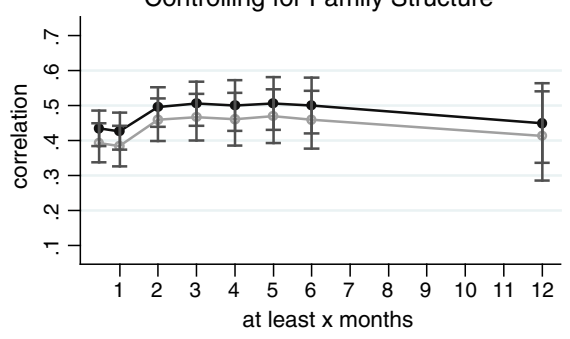

Sister correlations in prison sentence Controlling for All Family Background Variables

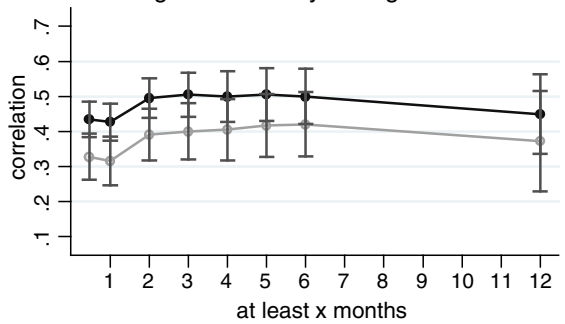

Fig. 4 Sibling correlations in prison controlling for parental income and education, parental criminality, and family structure. Note: We show the sibling correlations estimated with (without) controls in grey (black)

tance of parental criminality. The parents used in this study are quite old, which means that their crime data are heavily censored (recall that our crime data start in 
1973 when parents in our data are on average 39 years old). In order to examine this potential issue of measurement error in parental crime, we split our sample into two groups; the older cohorts born 1958-1962 with (on average) older parents and the younger cohorts born 1964-1968 with (on average) younger parents. If crime among the younger cohorts of parents accounts for a larger share of the sibling correlation than does crime among the older cohorts of parents, then this may indicate that measurement error in parental criminality is biasing our measures of its quantitative importance downwards. ${ }^{29}$

After splitting the sample this way, we see that the amount of the brother correlation in Crime that can be accounted for by parental criminality rises from 10 to $14 \%$. The amount of the sister correlation explained by parental criminality, however, remains fairly constant across samples, changing from 13 to $12 \%$ when moving from the older to the younger parents. Similar increases for brothers, and no increases for sisters, can be seen across all extensive margin variables. Importantly, we do not see the same increase in explanatory power of parental income and education if we rerun that experiment after splitting the sample into younger and older cohorts. Thus, we conclude that measurement error in parental criminality may bias the explanatory power of parental criminality downwards more for brothers than for sisters. Thus, parental criminality may explain the same amount of the variation among brothers as among sisters.

When we add controls for just family structure, the correlations in criminal convictions decrease by at most $19 \%$ for brothers (for "at least one crime") and $16 \%$ for sisters (for "at least one crime") compared to the baseline with no controls. The correlations in prison sentence length decrease by at most $15 \%$ for brothers (for "at least 2 weeks in prison"), while for sisters the decrease is never statistically significant.

These results suggest that both parental criminality and family structure are relatively more important in explaining sibling correlations in crime than parental education and income. One possible explanation for this is that both the parental criminality and family structure variables are themselves impacted by parental education and income, and thus controlling for either of these variables actually captures some of the effect of parental income and education in addition to the direct effect of parental criminality or family structure. While this is true to some extent, a factor analysis of our explanatory variables concludes that there are three clearly distinct factors. Factor 1 is based on parents' education and income. Factor 2 represents parental criminality. Factor 3 represents household structure. Mother's age at first birth, however, loads equally onto all three factors.

When we include all the above controls at once, the correlations in criminal convictions decrease by at most $27 \%$ for brothers (for "at least one crime") and

\footnotetext{
${ }^{29}$ As we suspected, only $23 \%$ of the older fathers have a conviction and $4 \%$ have a prison sentence, while $27 \%$ of the younger fathers have a conviction and $5 \%$ have a prison sentence. For mothers, we see that $8 \%$ of the older mothers have a conviction and $0.2 \%$ have a prison sentence, while $9 \%$ of the younger mothers have a conviction and $0.4 \%$ have a prison sentence.
} 
$26 \%$ for sisters (for "at least one crime"), and the correlations in prison sentence length decrease by at most $23 \%$ for brothers (for "at least 2 weeks in prison") and $26 \%$ for sisters (for "at least 1 month in prison"). We, therefore, conclude that around one fourth of the sibling similarities in criminal outcomes can be accounted for by our set of family-wide controls, suggesting that sibling associations in criminal behavior are driven mainly by factors common to siblings other than parental income and education, parental criminality, and family structure.

\subsection{Sibling spacing}

Siblings born many years apart may, in fact, experience quite dissimilar home environments. This could explain why our set of family-wide variables does not account for the majority of the sibling correlation. Household type at age 15 and household size at age 15 vary across siblings. But our measures of parental income, parental education, parental crime, father unknown, and mother's age at first birth do not. The influence that these variables may have on the environments experienced by children is not allowed to vary over time.

To gauge the importance of sibling spacing for our accounting exercise, we re-run the experiment using pairs of brothers and sisters born at most 4 years apart and compare these results to those obtained when using sibling pairs born 6 to 10 years apart. In Fig. 5, we see that our family-wide variables account for as much of the sibling correlation among widely spaced siblings as they do for closely spaced siblings. (For instance, the extensive margin correlations for brothers born within 4 years of each other and those born six or more years apart are both reduced by $26 \%$ when including the full set of controls). This implies that the larger correlation between closely spaced siblings is being driven by unobserved family factors that differ between these two types of siblings. It also implies that these unobservables are quite important. Sibling peer influences might be one such factor (see, e.g., Schrøter Joensen and Skyt Nielsen 2015). Other factors could include time-varying family factors or time-varying neighborhood influences.

\subsection{Sibling peer effects}

In this section, we attempt to explore to what extent our sibling correlations in crime are driven by direct sibling peer effects. That is, we examine if the criminal behavior of an individual directly influences the criminal behavior of their sibling. Our focus in these experiments is on unique sibling pairs, i.e., on families that contribute exactly one pair of siblings to our sample. We first examine the impact that older siblings' crime has on younger siblings' crime after controlling for both observable family characteristics and unobservable family effects. We then differentiate this direct sibling effect by gender.

Research emanating from several disciplines (including child psychology and child development) provides support for the hypothesis that older siblings influence younger siblings' risky behaviors and delinquency, while younger siblings 

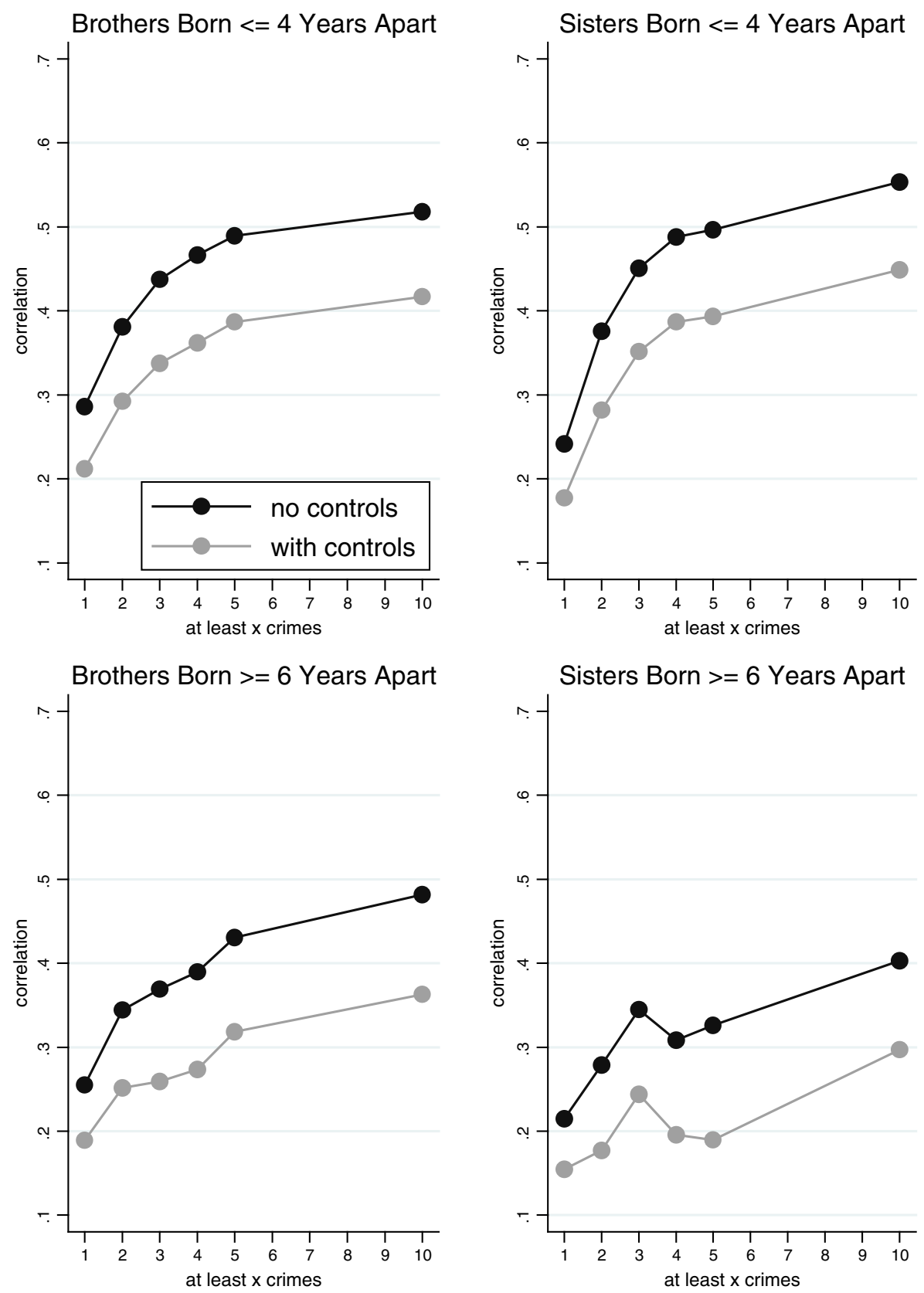

Fig. 5 Sibling correlations in crime for closely spaced siblings and widely spaced siblings with and without controls for family background

tend to have much less of a direct influence on older siblings' behaviors (see, e.g., Needle et al. 1986, Rodgers and Rowe 1988, Buhrmester 1992, Slomkowski 
et al. 2001). Empirical work done by economists lends further support to this hypothesis (Oettinger 2000; Ouyang 2004; Altonji et al. 2013). ${ }^{30}$ Two mechanisms stand out in this literature: (i) older siblings act as role models and (ii) older siblings act as suppliers of substances, opportunities, and/or delinquent peers.

Direct sibling effects may also be gender specific. A stronger same-sex transmission of criminal behavior could be an indication of the presence of role modeling. Role model identification theory implies that role models are more often of the same gender (Ruef et al. 2003). More generally, homophily is prevalent in many relationships; that is, individuals have a tendency to bond easier with similar others (McPherson et al. 2001).

In this section, we switch to using a panel estimator, since we intend to use the timing of siblings' crimes to help us identify potential sibling peer effects. Our working hypotheses are (i) that peer influences flow from older to younger siblings and (ii) that these influences will be stronger for same-sex siblings.

In Eq. 9, we estimate the raw association between a younger sibling's crime in year $t, C_{t}^{2}$, and the older sibling's lagged crime in year $t-1, C_{t-1}^{1}$,

$$
C_{t}^{2}=\beta_{0}+\rho C_{t-1}^{1}+u_{t}^{2}
$$

Superscript 2 denotes the younger sibling and superscript 1 denotes the older sibling. We then re-estimate this association including all of our shared family background controls, $X^{f}$, and age dummies, age ${ }_{t}^{2}$, at time $t$ for the younger sibling,

$$
C_{t}^{2}=\beta_{0}+\rho C_{t-1}^{1}+X^{f}+\operatorname{age}_{t}^{2}+\varepsilon_{t}^{2} .
$$

In order to estimate Eqs. 9 and 10, we have created an annual panel data set for the years 1973-1993. We restrict the analysis to sibling pairs with a maximum age difference of 10 years and to years when the younger sibling is at least 15 years old (the age of criminal majority in Sweden). Thus, for the younger siblings, we are including all peak years of crime (ages 18-21), as well as all available teenage years $(15+)$. We create annual extensive margin variables for all crimes and by crime type. Keep in mind, however, that individuals may have extensive margin values equal to 1 in more than 1 year, which makes the estimated results (as we shall see in a moment) look more similar to those of our intensive margin analysis than our extensive margin analysis. ${ }^{31}$ Equations 9 and 10 are estimated using logistic models (as are our sibling correlations). We report both odds ratios and sibling correlations. Standard errors are clustered on individuals (the younger sibling).

The results estimated from Eqs. 9 and 10 are reported in the first two columns of Table 4 for all crime. Having an older sibling who is convicted of at least one crime in year $t-1$ raises the younger sibling's odds of receiving at least one conviction in

\footnotetext{
${ }^{30}$ Schrøter Joensen and Skyt Nielsen (2015) report a causal influence of older male siblings' choice of academic curricula on their younger male siblings' choice of academic curricula.

${ }^{31}$ None of the results in the section change if we, instead, use the number of convictions each year, that is if we instead create a panel of annual intensive margin variables.
} 
Table 4 Estimates of potential sibling peer effects in crime

\begin{tabular}{|c|c|c|c|c|c|}
\hline & (1) & (2) & (3) & (4) & (5) \\
\hline$C_{t-1}^{1}$ & $\begin{array}{l}2.88^{* * *} \\
(0.046)\end{array}$ & $\begin{array}{l}2.01^{* * *} \\
(0.033)\end{array}$ & $\begin{array}{l}1.03 \\
(0.030)\end{array}$ & $\begin{array}{l}1.03 \\
(0.030)\end{array}$ & \\
\hline Sib. corr. & $\rho=0.41$ & $\rho \approx 0.28$ & $\rho \approx 0.01$ & $\rho \approx 0.01$ & \\
\hline$C_{t}^{1}$ & & & & $\begin{array}{l}1.19^{* * *} \\
(0.034)\end{array}$ & $\begin{array}{l}3.15^{* * *} \\
(0.050)\end{array}$ \\
\hline $\begin{array}{l}\text { Sib. corr. } \\
\text { Controls: }\end{array}$ & & & & Controls: & $\rho=0.41$ \\
\hline \multicolumn{2}{|c|}{ Family background } & Yes & Yes & Yes & \\
\hline \multicolumn{2}{|c|}{ Age younger sibling } & Yes & Yes & Yes & \\
\hline \multicolumn{2}{|c|}{ Age older sibling } & & Yes & Yes & \\
\hline \multicolumn{2}{|c|}{$C_{t-1}^{1}+C_{t+1}^{1}$} & & Yes & & \\
\hline \multicolumn{2}{|c|}{$C_{t-1}^{1}+C_{t}^{1}+C_{t+1}^{1}$} & & & Yes & \\
\hline Nr obs. & $1,831,259$ & $1,831,259$ & $1,831,259$ & $1,831,259$ & $1,831,259$ \\
\hline
\end{tabular}

Odds ratios (OR) are estimated using logistic regressions. Standard errors clustered on individuals, i.e., the younger sibling, are reported in parentheses. Family background controls include parental income and education, parental criminality, and family structure (household size at age 15, unknown father, mother's age at first birth, and household type at age 15). Sibling correlations in columns (1) and (5) are estimated using STATA's $x$ tlogit command. Sibling correlations reported in columns (2-4) are approximated using the following formula:

$\rho \approx\left(\mathrm{OR}^{\phi}-1\right) /\left(\mathrm{OR}^{\phi}+1\right)$, where $\phi$ is calibrated using the odds ratios and sibling correlations estimated in columns (1) and (5). In the first row of sibling correlations (involving $C_{t-1}^{1}$ ), $\phi$ is equal to 0.82 . In the second row of sibling correlations (involving $C_{t}^{1}$ ), $\phi$ is equal to 0.76

$* * * p<0.01$

year $t$ by 2.88 . The associated sibling correlation is 0.41 , which is in line with our intensive margin results reported earlier. When controlling for the full set of family background variables and the younger sibling's age at time $t$, the odds ratio (sibling correlation) is reduced by $30 \%$ (32\%). These reductions echo our previous results.

The question now is: How much of the remaining association can be ascribed to a direct sibling influence that the older sibling has on his/her younger sibling and how much is due to correlated random family effects that are unobservable? To answer this important question, Altonji et al. (2013) propose the use of a correlated randomeffects regression to estimate the direct sibling effect, which takes advantage of the temporal nature of sibling effects and relies on the assumption that younger siblings do not influence older siblings. ${ }^{32}$ They use the sum of the older sibling's crime at

\footnotetext{
${ }^{32} \mathrm{~A}$ second important identifying assumption is that parents do not change their behavior towards the younger sibling after the older sibling is caught committing a crime, e.g., that they do not monitor both children more stringently.
} 
$t-1$ and $t+1$ as a control for correlated random effects (i.e., the unobservable family component). Including this control, Eq. 10 can be re-written as

$$
C_{t}^{2}=\beta_{0}+\beta_{1}\left(C_{t-1}^{1}+C_{t+1}^{1}\right)+\lambda_{0} C_{t-1}^{1}+X^{f}+\operatorname{age}_{t}^{2}+\operatorname{age}_{t}^{1}+\varepsilon_{t}^{2},
$$

where $\lambda_{0}$, the coefficient on the early behavior, represents the direct sibling influence that the lagged crime of an older sibling has on his/her younger sibling. ${ }^{33,34}$ We can also allow for a contemporaneous effect, i.e., a direct influence of the older sibling's current crime, $C_{t}^{1}$, on the younger sibling's current crime

$$
C_{t}^{2}=\beta_{0}+\beta_{1}\left(C_{t-1}^{1}+C_{t}^{1}+C_{t+1}^{1}\right)+\lambda_{0} C_{t-1}^{1}+\lambda_{1} C_{t}^{1}+X^{f}+\mathrm{age}_{t}^{2}+\mathrm{age}_{t}^{1}+\xi_{t}^{2},
$$

where the contemporaneous effect is given by $\lambda_{1}$.

We report results from estimating Eqs. 11 and 12 in columns (3) and (4) in Table 4. Controlling for the correlated random effect appears to explain the remainder of the relationship between the younger sibling's crime at time $t$ and the older sibling's crime at $t-1$. That is, our estimate of $\lambda_{0}$ is small and statistically insignificant in both columns, suggesting that there is no direct effect of the older sibling's crime at time $t-1$ on the younger sibling's crime at time $t$. However, as shown in column 4, our estimate of $\lambda_{1}$ results in a statistically significant odds ratio of 1.19 and a sibling correlation of 0.07 . The results from estimating these regressions for each crime type follow the same pattern as above: no effect of the older sibling's lagged crime and a positive contemporaneous effect. Lastly, the contemporaneous sibling correlation in our panel data set is 0.41 (see column (5) of Table 4). This implies that a direct contemporaneous sibling peer effect could at most account for $100 * 0.07 / 0.41=$ $17 \%$ of the raw sibling correlation. But, much of this contemporaneous correlation could also simply be due to unobservable family-wide contemporaneous shocks.

We now turn to the gender-specific results. In Table 5, we show results from estimating Eq. 12 separately for the four different gender combinations of siblings: sister-sister, sister-brother, brother-sister, and brother-brother. The most important finding from the gender-specific analysis is that the positive contemporaneous effect is present for same-sex siblings but insignificant for mixed-sex siblings. Just as for the pooled sample, the effect of the older sibling's lagged crime is insignificant. The raw brother (sister) correlation is $0.36(0.43)$, which means that a potential direct contemporaneous same-sex sibling effect could at most account for $100 * 0.06 / 0.36=17 \%$ $(100 * 0.11 / 0.43=26 \%)$ of the raw correlation.

We draw two main conclusions from this exercise. First, we find no evidence of a direct influence of the older sibling's lagged crime on the younger sibling's crime. This result may indicate that lagged sibling effects are not important determinants of our sibling correlations in crime. However, having an older sibling commit a crime (and get convicted) may deter a younger sibling from committing crime by resulting

\footnotetext{
${ }^{33}$ This equation is derived from a pair of discrete choice models (one for each sibling) and relies on a set of very strong identifying assumptions. We refer the reader to Section 5.2 in Altonji et al. (2013) for a detailed discussion of these assumptions.

${ }^{34}$ Altonji et al. (2013) clearly recognize the advantage of the simplicity of the correlated random-effects approach but also note its disadvantages - namely that state dependence and non-stationarity with respect to age could bias the estimate of the older sibling's influence, though the direction of the bias is unknown.
} 
Table 5 Estimates of potential sibling peer effects in crime using different gender combinations of siblings

\begin{tabular}{lllll}
\hline & $(1)$ & $(2)$ & $(3)$ & $(4)$ \\
& F1F2 & F1M2 & M1F2 & M1M2 \\
\hline$C_{t-1}^{1}$ & 0.81 & 1.03 & 1.08 & 1.05 \\
Sib. corr. & $(0.116)$ & $(0.071)$ & $(0.087)$ & $(0.033)$ \\
$C_{t}^{1}$ & $\rho \approx-0.05$ & $\rho \approx 0.01$ & $\rho \approx 0.02$ & $\rho \approx 0.01$ \\
& 1.52 & 1.07 & 1.05 & 1.24 \\
Sib. corr. & $(0.223)^{* * *}$ & $(0.074)$ & $(0.081)$ & $(0.039)^{* * *}$ \\
Family background & $\rho \approx 0.11$ & $\rho \approx 0.02$ & $\rho \approx 0.01$ & $\rho \approx 0.06$ \\
Age younger sibling & Yes & Yes & Yes & Yes \\
Age older sibling & Yes & Yes & Yes & Yes \\
$C_{t-1}^{1}+C_{t}^{1}+C_{t+1}^{1}$ & Yes & Yes & Yes & Yes \\
Nr of observations & 425,593 & Yes & Yes & Yes \\
& & 464,553 & 462,589 & 478,524 \\
\hline
\end{tabular}

In the column titles, F1 denotes that the older sibling is female, M1 that the older sibling is male, F2 that the younger sibling is female, and M2 that the younger sibling is male. Odds ratios are estimated using logistic regressions. Standard errors clustered on individuals (the younger sibling) are reported in parentheses. Family background controls include parental income and education, parental criminality, and family structure (household size at age 15, unknown father, mother's age at first birth, and household type at age 15). Sibling correlations are approximated using the following formula, $\rho \approx\left(\mathrm{OR}^{\phi}-1\right) /\left(\mathrm{OR}^{\phi}-\right.$ 1 ), where $\phi$ is calibrated using the appropriate gender-specific or mixed-gender odds ratio and sibling correlation, both estimated without controls. See also the note to Table 4

$* * * p<0.01$

in an updating of their beliefs regarding expected punishment. Thus, our results may also result from positive (role model) and negative (deterrence) sibling peer effects that cancel each other out. Second, we find a positive and significant effect of the older sibling's current crime. This effect may indicate that there is a direct contemporaneous sibling effect, for instance because siblings provide each other with crime opportunities. ${ }^{35}$ Alternatively, siblings may be exposed to family- or neighborhoodspecific shocks, not captured by our family-wide control variables or by our controls

\footnotetext{
${ }^{35}$ The contemporaneous effect may be partly driven by siblings committing crimes together. We have access to data on co-offending (see Lindquist and Zenou 2014 for a description of these data). In these data, we see that siblings co-offend when they are teenagers and presumably still living together. Adult siblings rarely co-offend. In contrast to this, the size of our contemporaneous sibling effect does not vary substantially by siblings' age (results not reported here). Thus, we do not believe that co-offending is the main driver of the contemporaneous effect. Furthermore, girls rarely co-offend with their sisters. Despite this, estimates of the contemporaneous sister effect are still significant. Girls are more likely to co-offend with a brother than a sister. But we see no contemporaneous effect for mixed-sex siblings. These results also speak against co-offending as being the main source of the contemporaneous same-sex sibling effect that we see in our data.
} 
for the correlated random effects, inducing them to commit crimes at the same point in time.

\subsection{Neighborhood effects}

Although we have been able to account for a significant share of the sibling correlation, an even larger share remains unexplained. In this section, we explore the potential role of neighborhood effects that are shared by siblings. Studies in economics suggest that neighborhoods may have causal effects on individual crime (e.g., Ludwig et al. 2001, Kling et al. 2005, and Damm and Dustmann 2014). In contrast to these studies, Sariaslan et al. (2013) present evidence that Swedish neighborhoods do not appear to have a direct effect on violent crime and substance abuse among youths aged 15 to 20 , at least not at the extensive margin. ${ }^{36}$

Here, we present neighborhood correlations in crime at the extensive and intensive margin broken down by crime type and gender. In the absence of familyneighborhood interaction effects, these neighborhood correlations act as an upper bound on the part of the sibling correlation that shared neighborhood environments could potentially account for (see Solon et al. 2000 and our discussion in Section 2). To net out sorting into neighborhoods, we include all of the family-wide control variables used in the previous section.

We define a neighborhood as the parish that a child lived in at (or around) age 15. ${ }^{37}$ Parishes are the smallest administrative unit in Sweden. For the cohorts that we study in this paper, parishes correspond quite closely to school districts (catchment areas). We use data from the 1975, 1980, and 1985 bidecennial censuses to assign parish codes. From the 1980 census, we have, for example, information from 2,602 parishes. The smallest parish contains only 1 family; the median number of families is 43 , the mean is 157 , and the largest contains 3,034 families.

We report the extensive margin neighborhood correlations in Table 6. The neighborhood correlation in crime for all individuals is 0.01 , suggesting that (at most) $1 \%$ of the total variation in crime can be explained by factors that individuals growing up in the same neighborhood share. Investigating the neighborhood correlations for each of the crime types separately, the correlation is 0.02 for property crime, 0.02 for violent crime, and 0.01 for other crime. For prison, the neighborhood correlation is 0.02. The neighborhood correlation is thus lower for other crimes than for property crimes, violent crimes, and prison.

The highest correlations are the correlations for property crime for men and women, which are both 0.03 . These correlations indicate that at most $3 \%$ of the variation in property crime can be attributed to shared neighborhood factors. These

\footnotetext{
${ }^{36}$ Most Swedish studies using observational data tend to find limited influences of neighborhoods on children's outcomes (e.g., Brännström 2004 and Lindahl 2011). However, several quasi-experimental studies have demonstrated that growing up in an ethnic enclave in Sweden does have an important effect on children's outcomes (e.g., Edin et al. 2003 and Åslund et al. 2011).

${ }^{37}$ We cannot get information on schools attended nor on the Small Area Marketing Statistics used to define neighborhoods in Sariaslan et al. (2013), since the cohorts we study are too old.
} 
Table 6 Extensive margin neighborhood correlations

\begin{tabular}{llll}
\hline & Men and women & Men & Women \\
\hline \multirow{2}{*}{ Crime } & 0.008 & 0.010 & 0.011 \\
& $(0.001)$ & $(0.001)$ & $(0.001)$ \\
Property crime & 0.023 & 0.025 & 0.026 \\
& $(0.002)$ & $(0.002)$ & $(0.003)$ \\
Violent crime & 0.016 & 0.017 & 0.012 \\
& $(0.002)$ & $(0.002)$ & $(0.004)$ \\
Other crime & 0.007 & 0.009 & 0.007 \\
Prison & $(0.001)$ & $(0.001)$ & $(0.001)$ \\
Nr of observations & 0.020 & 0.021 & 0.021 \\
& $(0.002)$ & $(0.002)$ & $(0.007)$ \\
\hline
\end{tabular}

Neighborhood correlations are estimated using STATA's xtlogit command after first randomly drawing one individual from each family. This random draw is done separately for each of the three sample used. All outcome variables are dichotomous. Birth year and gender dummies are included. Controls for parental education and income, parental criminality, and family structure are also included in order to net out sorting into neighborhoods. Standard errors are in parentheses

should be contrasted with our brother and sister correlations in "at least one property crime," which are 0.38 and 0.34 , respectively. Thus, neighborhood effects appear to be able to explain approximately $7 \%$ of the sibling correlation in property crime at the extensive margin. Given that we have included all of the family-wide controls used in Section 5, these $7 \%$ can be added on to the $27 \%$ explained in the previous section. Thus, it appears that we can account for as much as one third of the sibling correlation at the extensive margin.

The intensive margin neighborhood correlations are again computed using binary outcome variables. We show the neighborhood correlations for up to 10 crimes and up to 1 year in prison in Fig. 6. In Appendix Fig. 8, we show separate figures for each crime type.

Similar to our sibling correlations, neighborhood correlations also increase along the intensive margin. For women, the increase in the neighborhood correlation in aggregate crime is from 0.011 (for "at least 1 crime") to 0.045 (for "at least 10 crimes") and, for prison, it rises from 0.021 (for "at least 2 weeks") to 0.059 (for "at least 1 year"). For men, the increase in the neighborhood correlation in aggregate crime is from 0.010 (for "at least 1 crime") to 0.033 (for "at least 10 crimes") and, for time in prison, it rises from 0.021 (for "at least 2 weeks") to 0.048 (for "at least 1 year").

Overall, neighborhood correlations are quite small for all but the most severe offenders, and even these are much lower than their corresponding sibling correlations. If the simple linear additive model posited in Eq. 1 is correct, then this result would indicate that factors shared by siblings other than shared neighbor- 

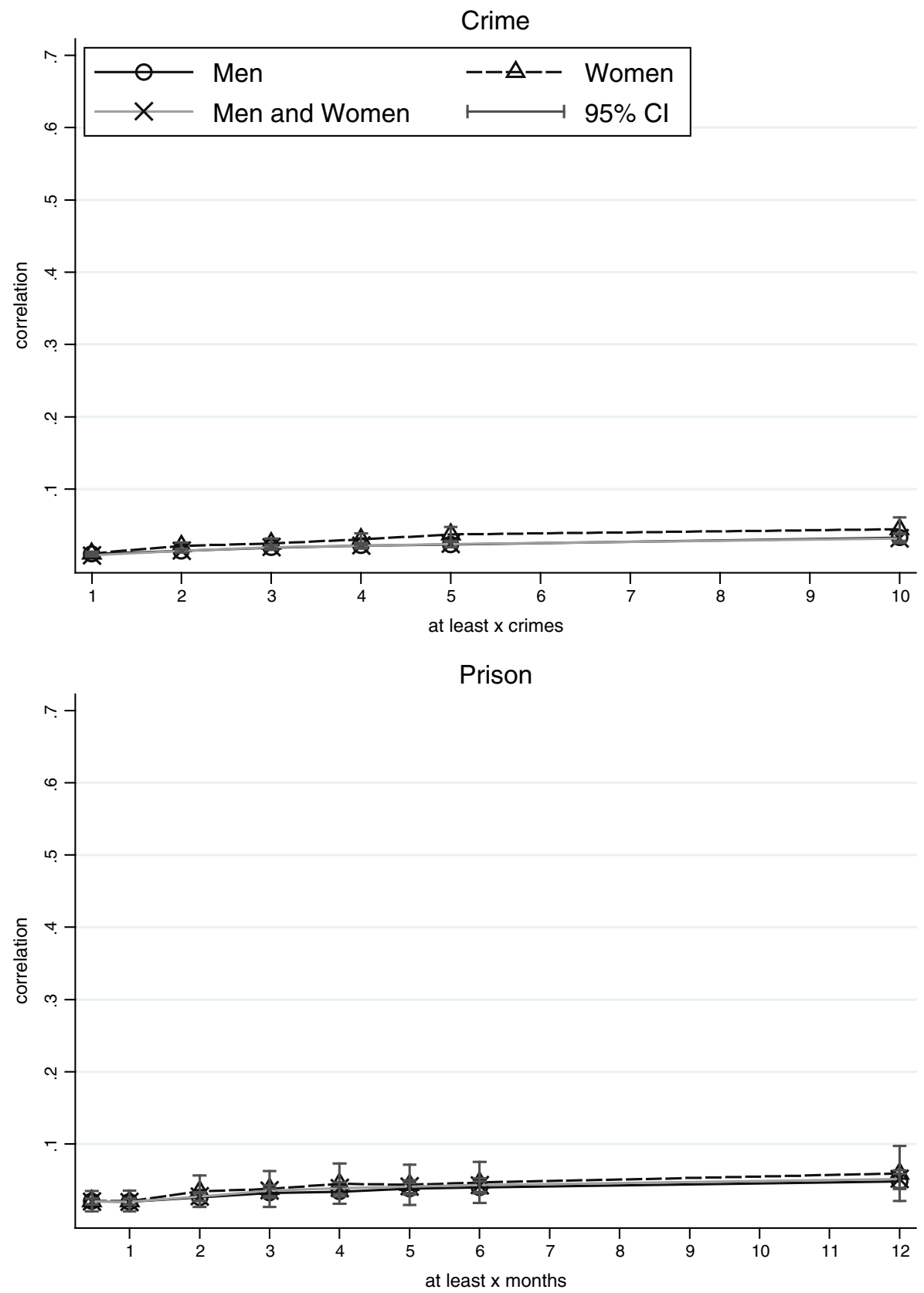

Fig. 6 Neighborhood correlations in crime and prison

hoods are more important for an individual's criminality than factors shared by individuals growing up in the same neighborhood. At the same time, if we relate 
the size of our estimated neighborhood correlations to the size of the comparable sibling correlations, neighborhood correlations have the potential to explain between 7 and $13 \%$ of the sibling correlation beyond that explained by our full set of family-specific control variables. This is similar to the amount accounted for by parental education and income. As such, neighborhoods cannot be disregarded as unimportant.

One potential explanation for our small estimated neighborhood correlations is that our definition of neighborhoods is too broad, both in the geographical sense and in the sense that neighborhoods may not map well into peer groups. Alternatively, one might want to focus more on the schools that children attend (as in Gaviria and Raphael 2001, Calvó-Armengol et al. 2009, and Liu et al. 2012) or on close neighbors. Sariaslan et al. (2013) study younger cohorts and, therefore, have access to more narrow measures of neighborhoods. They look within the Small Area Marketing codes created by Statistics Sweden to define small, homogenous neighborhoods. They also look within schools. But they still find no large neighborhood effect.

Brännström (2004) argues that the small neighborhood effects reported in many Swedish studies may be due to the success of the Swedish welfare state. This is certainly one possibility. For the USA, Johnson (2007) reports large neighborhood correlations in criminal behavior and incarceration. He also reports that growing up in low-quality neighborhoods increases the likelihood that one has ever been incarcerated. On the other hand, neighborhood correlations in educational attainment are quite similar in the USA and Sweden and quite small. ${ }^{38}$ It may, therefore, be hard to argue that our result is "Sweden specific". Lastly, one should keep in mind that we are studying the overall neighborhood effect and not the effect of growing up in an extremely disadvantaged neighborhood. ${ }^{39}$

To assess the impact that neighborhood quality might have on our sibling correlations, we run an additional experiment. We start by defining a measure of neighborhood quality based on the average education level of parents in the neighborhood, the average income level of parents, and the share of immigrant parents in each neighborhood. ${ }^{40}$ We then create a dummy variable equal to one for the $10 \%$ of our sibling sample living in the highest quality neighborhoods and a second dummy variable equal to one for the $10 \%$ of our sibling sample living in the lowest quality neighborhoods. We estimate neighborhood

\footnotetext{
${ }^{38}$ For the USA, see Solon et al. (2000). For Sweden, see Lindahl (2011).

${ }^{39}$ The Moving to Opportunity program focuses more on helping families leave extremely low-quality neighborhoods (Ludwig et al. 2001; Kling et al. 2005). Krivo and Peterson (1996) also study the connection between particularly disadvantaged neighborhoods and crime.

${ }^{40}$ Neighborhood quality refers to the characteristics of all of the parents living in the same parish as the sibling when the sibling was 15 years old. We first create three different percentile rankings for each parish: one based on parental education, a second based on parental income, and a third based on the share of parents who were not born in Sweden. Immigration status has been included in order to reflect the potential effects of segregation, discrimination, and the feeling of social exclusion that is often discussed in the Swedish debate concerning troubled neighborhoods. These three percentile rankings are then weighted equally into a final percentile ranking of neighborhood quality.
} 
correlations for high- and low-quality neighborhoods, and we produce new estimates of the sibling correlation for siblings living in these high- and low-quality neighborhoods. ${ }^{41}$

In Table 7, we see that the neighborhood correlations are consistently higher in low-quality neighborhoods than in high-quality neighborhoods. More importantly, the ratio between the neighborhood correlation and the sibling correlation is always larger for low-quality neighborhoods than for high-quality neighborhoods. This means that neighborhood effects can potentially explain more of the sibling correlation in low-quality neighborhoods, which leads us to conclude that neighborhood quality may be one of the factors that makes siblings similar in terms of their criminal behavior. However, such neighborhood effects are still smaller in magnitude than the roles played by parental criminality and family structure.

\subsection{Family and neighborhood interaction effects}

It is important to keep in mind that any discussion of the relative importance of family versus neighborhood effects in accounting for the sibling correlation is only really meaningful in the linear additive world described by Eq. 1. If important familyneighborhood interaction effects do exist, then interpreting the results from our accounting exercise is no longer straightforward. For example, the effect of parental education on children's outcomes may be quite different in a neighborhood with good schools versus one with bad schools. Alternatively, the impact of ethnicity on outcomes may depend on the number of co-ethnics a person lives close to (see, e.g., Edin et al. 2003 and Åslund et al. 2011).

In principle, we would like to test a version of the following random-effects model,

$$
c_{i f n}=\mu+a_{f}+a_{f} b_{n}+b_{n}+e_{i f n},
$$

which includes a family-neighborhood interaction term, $a_{f} b_{n}$, in order to ascertain whether or not there exist quantitatively meaningful interaction effects. If not, then the linear additive model may actually be a good representation of the data, even though we know that it is a highly stylized model. In practice, however, the computational burden of estimating this two-way crossed-effects model with an interaction term is extremely challenging (given the very large number of families and neighborhoods in our data). But, more importantly, the ideal data needed to estimate this model simply do not exist-i.e., two relatively closely spaced siblings who grew up in different neighborhoods (of varying quality), but who still lived with both parents in the same intact family.

\footnotetext{
${ }^{41}$ In this exercise, our full set of control variables and age and gender dummies are included in all estimations of both the neighborhood correlation and the sibling correlation. We want to see how much of the unexplained part of the sibling correlation could be potentially explained by differences in neighborhood quality. In order to do this, we need to control for sorting across different types of neighborhoods that could affect the size of both the neighborhood and the sibling correlation.
} 
Table 7 Sibling and neighborhood correlations in high- and low-quality neighborhoods

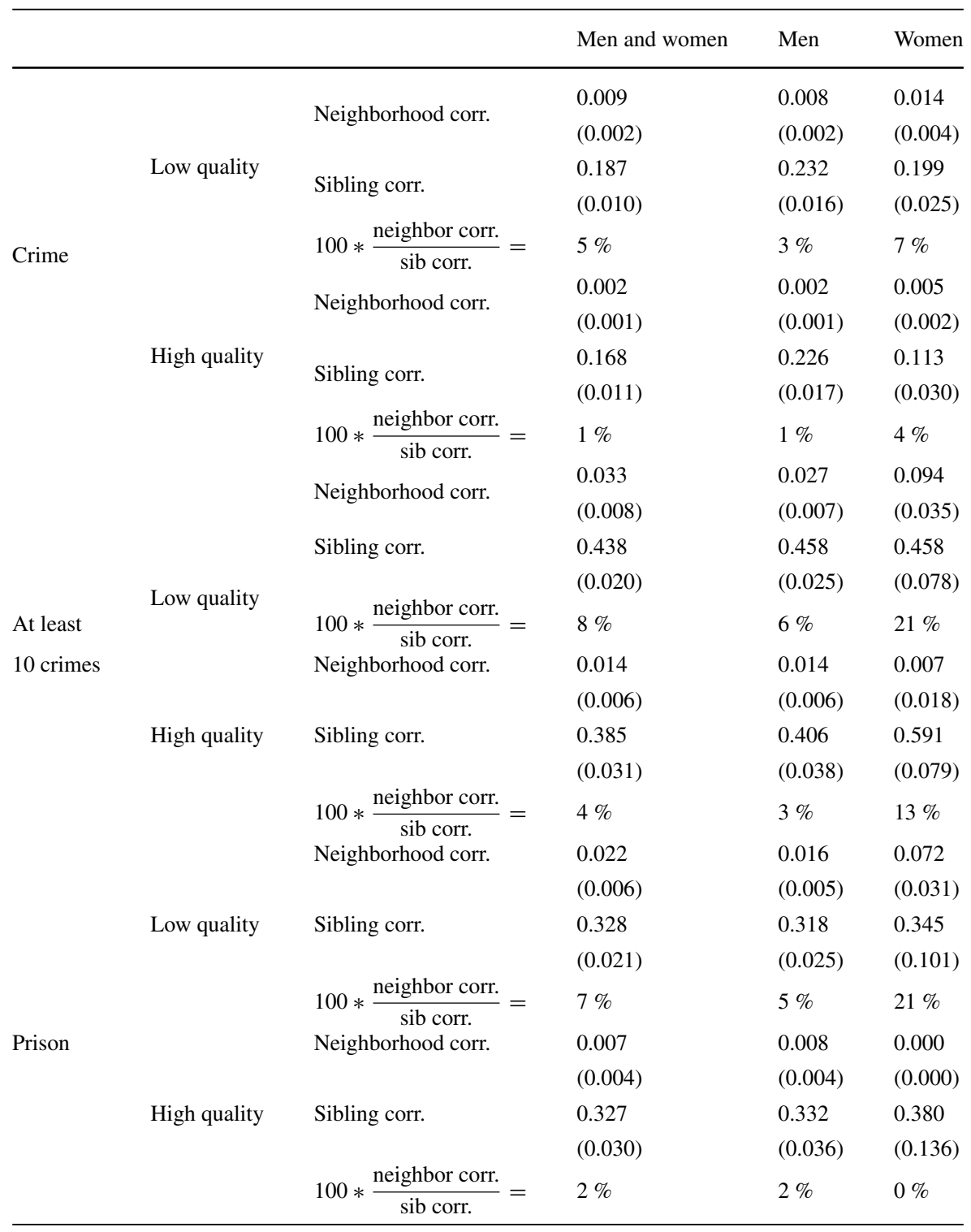

Neighborhood correlations are estimated using STATA's xtlogit command after first randomly drawing one individual from each family. This random draw is done separately for each of the three samples used. All outcome variables are dichotomous. Birth year and gender dummies are included. Controls for parish size, parental education and income, family structure, and parental criminality are also included in order to net out sorting into neighborhoods. Sibling correlations are estimated using STATA's $x$ tlogit command. All outcome variables are dichotomous. Birth year and gender dummies are included. Controls for parental education and income, parental criminality, and family structure are included, as are birth year and gender dummies. Singletons are included, except when estimating the sibling correlations for the mixed siblings 
Table 8 Interaction effects between family SES and average neighborhood quality in a model of crime at the extensive margin

\begin{tabular}{|c|c|c|c|c|c|}
\hline & Crime & Property crime & Violent crime & Other crime & Prison \\
\hline Fam $1 \times$ neighbor 1 & $\begin{array}{l}0.946^{* *} \\
(0.027)\end{array}$ & $\begin{array}{l}0.917^{* *} \\
(0.032)\end{array}$ & $\begin{array}{l}0.916^{*} \\
(0.046)\end{array}$ & $\begin{array}{l}0.969 \\
(0.029)\end{array}$ & $\begin{array}{l}0.912^{*} \\
(0.050)\end{array}$ \\
\hline Fam $1 \times$ neighbor 2 & $\begin{array}{l}0.954^{*} \\
(0.026)\end{array}$ & $\begin{array}{l}0.979 \\
(0.033)\end{array}$ & $\begin{array}{l}1.005 \\
(0.050)\end{array}$ & $\begin{array}{l}0.966 \\
(0.028)\end{array}$ & $\begin{array}{l}1.043 \\
(0.057)\end{array}$ \\
\hline Fam $1 \times$ neighbor 4 & $\begin{array}{l}1.098^{* * *} \\
(0.033)\end{array}$ & $\begin{array}{l}1.120^{* * *} \\
(0.040)\end{array}$ & $\begin{array}{l}1.135^{* *} \\
(0.059)\end{array}$ & $\begin{array}{l}1.099^{* * *} \\
(0.035)\end{array}$ & $\begin{array}{l}1.227^{* * *} \\
(0.070)\end{array}$ \\
\hline Fam $1 \times$ neighbor 5 & $\begin{array}{l}1.058^{*} \\
(0.035)\end{array}$ & $\begin{array}{l}1.042 \\
(0.041)\end{array}$ & $\begin{array}{l}1.042 \\
(0.061)\end{array}$ & $\begin{array}{l}1.069^{*} \\
(0.038)\end{array}$ & $\begin{array}{l}1.066 \\
(0.069)\end{array}$ \\
\hline Fam $2 \times$ neighbor 1 & $\begin{array}{l}0.992 \\
(0.027)\end{array}$ & $\begin{array}{l}1.008 \\
(0.034)\end{array}$ & $\begin{array}{l}0.959 \\
(0.046)\end{array}$ & $\begin{array}{l}1.013 \\
(0.029)\end{array}$ & $\begin{array}{l}0.997 \\
(0.054)\end{array}$ \\
\hline Fam $2 \times$ neighbor 2 & $\begin{array}{l}0.964 \\
(0.025)\end{array}$ & $\begin{array}{l}0.974 \\
(0.032)\end{array}$ & $\begin{array}{l}0.986 \\
(0.048)\end{array}$ & $\begin{array}{l}0.970 \\
(0.027)\end{array}$ & $\begin{array}{l}0.956 \\
(0.052)\end{array}$ \\
\hline Fam $2 \times$ neighbor 4 & $\begin{array}{l}0.997 \\
(0.027)\end{array}$ & $\begin{array}{l}0.985 \\
(0.033)\end{array}$ & $\begin{array}{l}1.041 \\
(0.051)\end{array}$ & $\begin{array}{l}1.024 \\
(0.030)\end{array}$ & $\begin{array}{l}1.036 \\
(0.057)\end{array}$ \\
\hline Fam $2 \times$ neighbor 5 & $\begin{array}{l}1.047 \\
(0.030)\end{array}$ & $\begin{array}{l}1.000 \\
(0.036)\end{array}$ & $\begin{array}{l}0.989 \\
(0.053)\end{array}$ & $\begin{array}{l}1.099^{* * *} \\
(0.034)\end{array}$ & $\begin{array}{l}1.036 \\
(0.061)\end{array}$ \\
\hline Fam $4 \times$ neighbor 1 & $\begin{array}{l}1.004 \\
(0.029)\end{array}$ & $\begin{array}{l}0.964 \\
(0.035)\end{array}$ & $\begin{array}{l}0.961 \\
(0.051)\end{array}$ & $\begin{array}{l}1.042 \\
(0.032)\end{array}$ & $\begin{array}{l}1.049 \\
(0.062)\end{array}$ \\
\hline Fam $4 \times$ neighbor 2 & $\begin{array}{l}0.998 \\
(0.027)\end{array}$ & $\begin{array}{l}1.013 \\
(0.035)\end{array}$ & $\begin{array}{l}0.954 \\
(0.050)\end{array}$ & $\begin{array}{l}1.018 \\
(0.030)\end{array}$ & $\begin{array}{l}1.035 \\
(0.061)\end{array}$ \\
\hline Fam $4 \times$ neighbor 4 & $\begin{array}{l}1.007 \\
(0.027)\end{array}$ & $\begin{array}{l}0.973 \\
(0.032)\end{array}$ & $\begin{array}{l}0.989 \\
(0.049)\end{array}$ & $\begin{array}{l}1.024 \\
(0.029)\end{array}$ & $\begin{array}{l}1.048 \\
(0.059)\end{array}$ \\
\hline Fam $4 \times$ neighbor 5 & $\begin{array}{l}0.968 \\
(0.027)\end{array}$ & $\begin{array}{l}0.897^{\text {*** }} \\
(0.031)\end{array}$ & $\begin{array}{l}0.918 \\
(0.048)\end{array}$ & $\begin{array}{l}1.012 \\
(0.030)\end{array}$ & $\begin{array}{l}0.940 \\
(0.055)\end{array}$ \\
\hline Fam $5 \times$ neighbor 2 & $\begin{array}{l}1.071^{* *} \\
(0.033)\end{array}$ & $\begin{array}{l}1.077^{*} \\
(0.045)\end{array}$ & $\begin{array}{l}1.021 \\
(0.067)\end{array}$ & $\begin{array}{l}1.079^{* *} \\
(0.036)\end{array}$ & $\begin{array}{l}1.066 \\
(0.079)\end{array}$ \\
\hline Fam $5 \times$ neighbor 4 & $\begin{array}{l}0.984 \\
(0.028)\end{array}$ & $\begin{array}{l}1.005 \\
(0.037)\end{array}$ & $\begin{array}{l}0.938 \\
(0.055)\end{array}$ & $\begin{array}{l}1.000 \\
(0.030)\end{array}$ & $\begin{array}{l}0.988 \\
(0.065)\end{array}$ \\
\hline Fam $5 \times$ neighbor 5 & $\begin{array}{l}0.991 \\
(0.027)\end{array}$ & $\begin{array}{l}0.982 \\
(0.036)\end{array}$ & $\begin{array}{l}0.854^{* * *} \\
(0.050)\end{array}$ & $\begin{array}{l}0.990 \\
(0.030)\end{array}$ & $\begin{array}{l}0.886^{*} \\
(0.058)\end{array}$ \\
\hline Observations & 734,520 & 734,520 & 734,520 & 734,520 & 734,520 \\
\hline
\end{tabular}

Coefficients are odds ratios from logistic regressions. Standard errors in parentheses are robust. All regressions include birth year and gender dummies. Controls for parish size, family SES, family structure, parental criminality, and neighborhood quality are also included. Family SES 3 and neighborhood quality 3 are the reference categories

* Significant at $10 \%$

** Significant at $5 \%$

$* * *$ Significant at $1 \%$ 
Thus, we consider an alternative test for the presence of family-neighborhood interaction effects that uses standard regression techniques (see, e.g., Winkleby et al. 2006). Specifically, we use our neighborhood quality index to place neighborhoods into quality quintiles, with 1 being the lowest and 5 the highest. We then create a similar index for family socio-economic status based on the incomes and education levels of both parents. Families are also placed into five SES quintiles, with 1 being the lowest and 5 the highest. To look for significant interaction effects, we estimate different versions of the following equation:

$$
\begin{aligned}
& \text { Crime }_{i f n}=\beta_{0}+\beta_{1} \text { age }_{i}+\beta_{2} \text { sex }_{i}+\beta_{3} \text { family SES }_{i f}+\beta_{4} \text { neighborhood SES } \text { in } \\
& +\beta_{5} \text { family } \mathrm{SES}_{i f} \times \text { neighborhood } \mathrm{SES}_{i n}+\beta_{6} \text { neighborhood size }{ }_{i n} \\
& +\beta_{7} \text { family structure }_{i f}+\beta_{8} \text { parental crime }_{i f}+\varepsilon_{i f n} \text {. }
\end{aligned}
$$

We estimate Eq. 14 using a logistic regression and report odds ratios. We use neighborhood quality 3 and family SES 3 as the excluded categories and allow all other levels to interact. What we are mainly interested in here is the sign, size, and significance of the set of interaction effects given by $\beta_{5}$.

Estimation results are presented in Table 8. Although most of the estimated odds ratios are small and statistically insignificant, we do see two distinct patterns. First, individuals from families that are "well matched" with neighborhoods, i.e., SES 1 families living in SES 1 neighborhoods and SES 5 families living in SES 5 neighborhoods, appear to experience a small, but statistically significant, protective effect. Second, siblings from low-SES families (SES 1) fair worse if they live in relatively high-SES areas (quality 4 and 5) at age 15. This second result could simply be due to negative selection; for instance, these families may have been placed by the social services in these neighborhoods. If this is the case, then these significant coefficients do not represent true interaction effects. Alternatively, it could be that a sense of relative deprivation and/or frustration gives rise to a higher crime rate among those who come from low-SES families but grow up in relatively high-quality neighborhoods.

In summary, studying family-neighborhood interaction effects is a difficult task. But our regression analysis indicates that nontrivial interaction effects may exist. However, controlling for these family-neighborhood interactions directly in our correlations analyses does not account for any additional share of the observed sibling crime correlations. ${ }^{42}$

\footnotetext{
${ }^{42}$ If we add the interaction effects as controls to the fixed part of our mixed-effects model, they can (on their own) account for at most 4-5\% of the sibling correlation depending on the measure of crime considered. If we simply add them as additional controls along with our full set of controls, then they do not provide any additional accounting power. They add nothing that is not already accounted for by the direct effects.
} 


\section{Conclusion}

Our analysis of sibling correlations in criminal behavior yields five main findings. First, we find that family background and community factors shared by siblings account for $24 \%$ of the variation in the likelihood of having any conviction. Second, we find even larger sibling correlations for measures of the intensity and severity of the criminal career: violent and property offenses versus other offenses, the likelihood of incarceration, the number of convictions, and longer prison sentences. These patterns are similar across (i) crime types, (ii) male, female, and mixed sibling pairs, and (iii) siblings more and less closely spaced. Third, our analysis of which family and community background characteristics account for the sibling crime correlations suggests that neighborhood identifiers and parental education and income play a relatively less important role than parental criminality and family structure. These results are in line with the previous literature on intergenerational crime. Neighborhood effects, however, tend to receive much more attention in the US literature. Fourth, all of these controls taken together still only explain one third of the sibling crime correlation, even for siblings spaced close together. Fifth, siblings spaced more closely together are more similar in terms of their criminal behavior.

Several important caveats must be placed on the interpretation of our quantitative accounting exercise. First, when discussing the relative importance of different control variables, one must keep in mind that the metric used in this paper to discuss the importance of different family-wide and neighborhood variables is the degree to which they lower the sibling correlation after being included as controls in the fixed part of our mixed-effects model. This is not the same as saying which effect would be the most policy relevant or cost-effective-although our hope is that a better understanding of the sibling correlation may, in the long run, help us to better understand the etiology of crime and, hence, aide in the design of better policy.

A second caveat is that our accounting exercise relies on the use of a simple, linear additive model. The existence of meaningful interaction effects would make it much harder to determine the relative importance of one factor over another. Third, the results presented in this paper are conditional on the structure of the environment in place in Sweden during the time period studied, and cannot readily be extended to make statements about the importance of (for example) neighborhood effects in the USA today. However, the fact that sibling correlations in crime are so high, even in Sweden with its high degree of relative income equality and extensive welfare state polices, should be of great interest to a broader audience. It really does put the spotlight on the role of family background and circumstances as important determinants of criminal behavior. A final caveat - and our fourth result listed above-is that it is striking that we are only able to account for one third of the large sibling correlation. 
This leaves us with the question of what actually does explain the sibling correlation in crime. Of course, we recognize that there are a number of mechanisms that our limited set of control variables does not capture. One possibility is genes and inherited characteristics that are correlated with criminal behavior. For instance, adoption studies that use the criminal records of the biological and adoptive parents to disentangle the importance of pre-birth (genes, prenatal environment, and perinatal conditions) and post-birth factors for generating intergenerational criminal relationships find evidence that pre-birth factors do play a significant role (Hjalmarsson and Lindquist 2013). Twin studies also report an important role for genetic factors in the etiology of antisocial behavior and crime (Ishikawa and Raine 2002; Eley et al. 2013). We would argue, however, that by controlling for the education, income, and criminal behavior of both biological parents, we have indeed controlled for most of the relevant genetic factors (albeit very imprecisely).

Using survey data from the Stockholm Birth Cohort, Björklund et al. (2010) show that parental involvement in school work, parenting practices, and maternal attitudes are important for generating sibling similarities in their adult incomes. In particular, a mother's willingness to plan and save for the future appears to matter. These remain important even after controlling for measures of parental income and education, family structure, and social problems. There is also increasing evidence that siblings may have a large influence on each other through sibling peer effects (see, e.g., Rowe and Farrington 1997, Altonji et al. 2013 and Schrøter Joensen and Skyt Nielsen 2015). However, we are not able to provide clear evidence of this in our context. Lastly, we have only begun to scratch the surface on understanding the potential role of family-neighborhood interaction effects. Continued work in the area of neighborhood effects, peer effects, sibling peer effects, and sibling similarities in criminal behavior is one avenue for moving beyond the analysis of statistical risk factors and into the realm of understanding the mechanisms underlying antisocial behavior and crime.

Acknowledgments We would like to thank Anders Björklund, Fredrik Carlsson, Magnus Johannesson, Mikael Lindahl, Erdal Tekin, two anonymous referees, and seminar participants at EALE 2013, Stockholm School of Economics, and ASSA 2014 for their valuable comments and suggestions. Karin Hederos Eriksson and Matthew Lindquist gratefully acknowledge financial support from the Swedish Research Council for Health, Working Life and Welfare (FORTE).

Open Access This article is distributed under the terms of the Creative Commons Attribution 4.0 International License (http://creativecommons.org/licenses/by/4.0/), which permits unrestricted use, distribution, and reproduction in any medium, provided you give appropriate credit to the original author(s) and the source, provide a link to the Creative Commons license, and indicate if changes were made.

\section{Appendix}

Figures 7, 8, 9, 10, and 11 

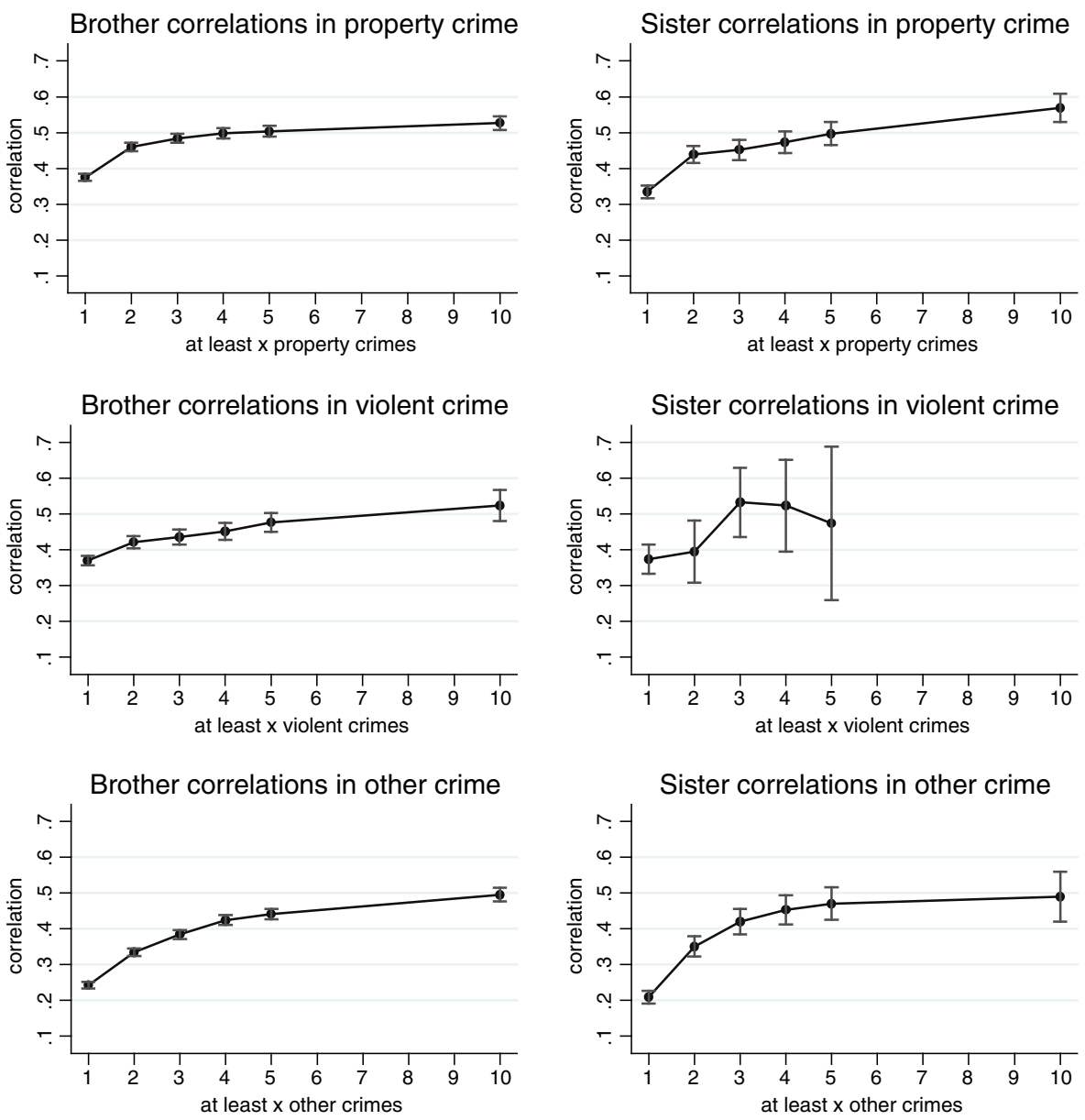

Fig. 7 Sibling correlations in property crime, violent crime, and other crime 

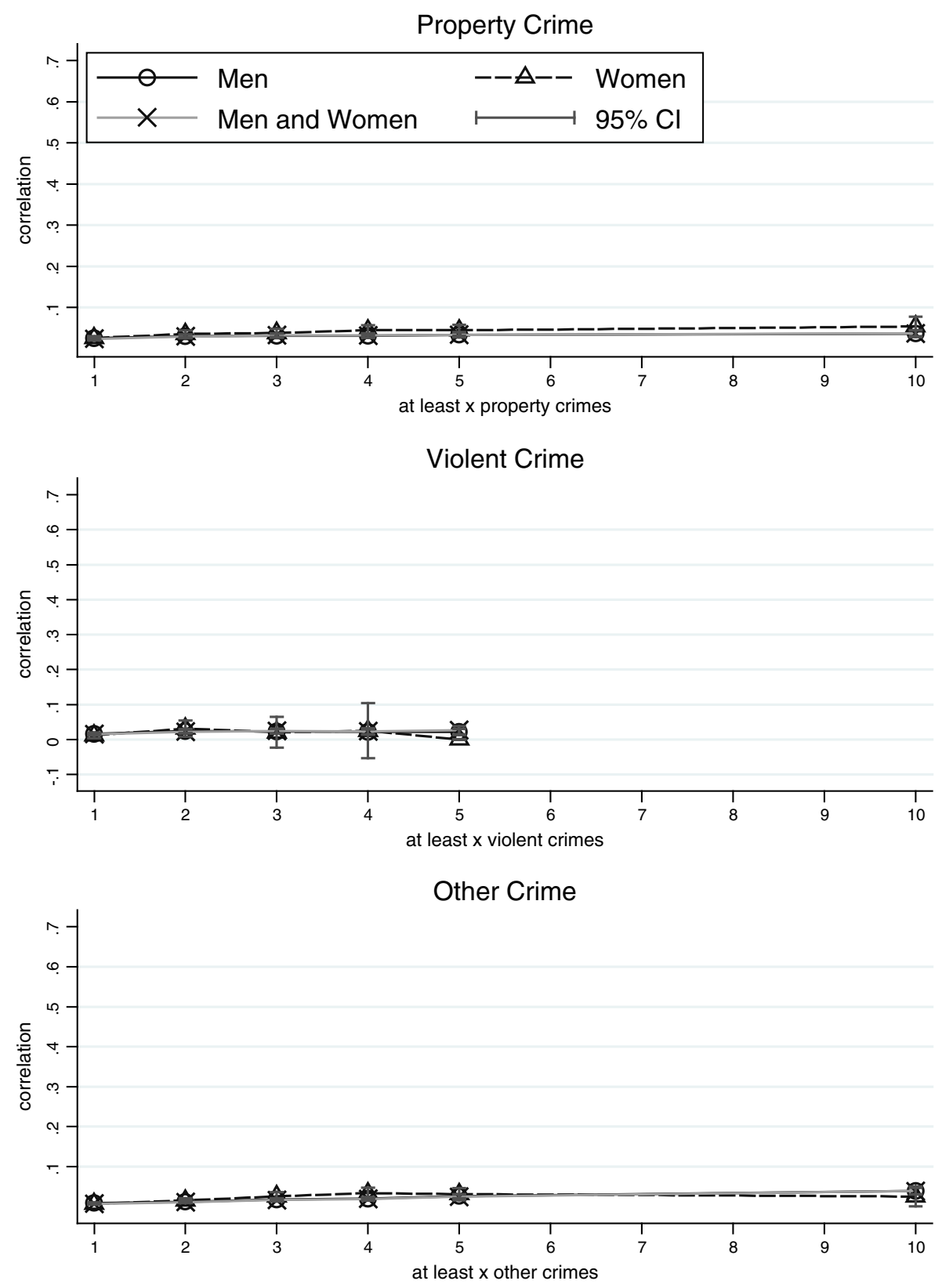

Fig. 8 Neighborhood correlations in property crime, violent crime, and other crime 
Brother correlations in property crime Controlling for Parental Income and Education

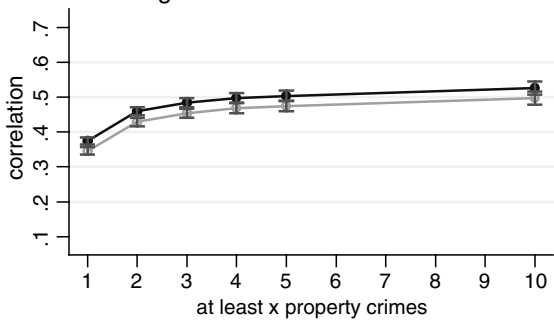

Brother correlations in property crime Controlling for Parental Criminality

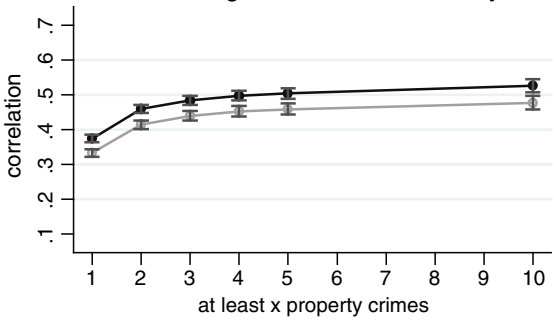

Brother correlations in property crime Controlling for Family Structure

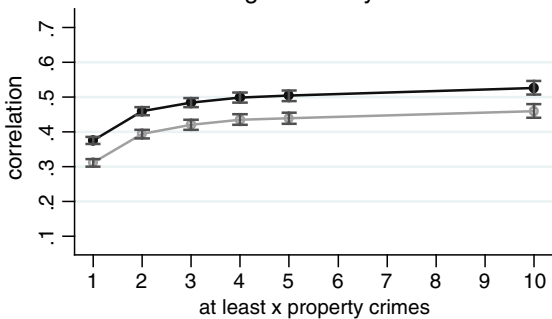

Brother correlations in property crime Controlling for All Family Background Variables

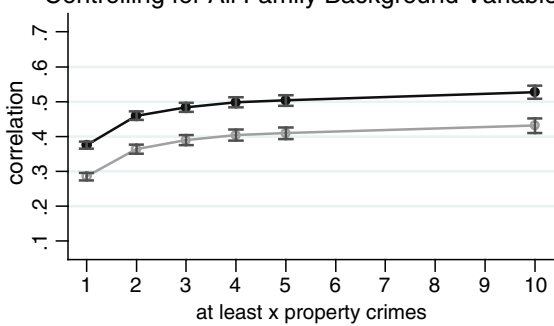

Sister correlations in property crime Controlling for Parental Income and Education

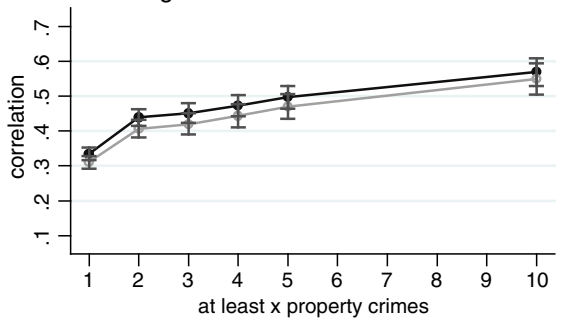

Sister correlations in property crime Controlling for Parental Criminality

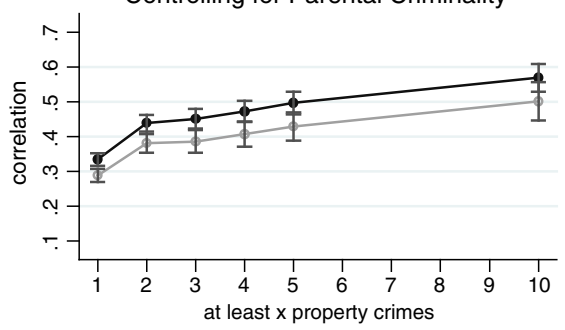

Sister correlations in property crime Controlling for Family Structure

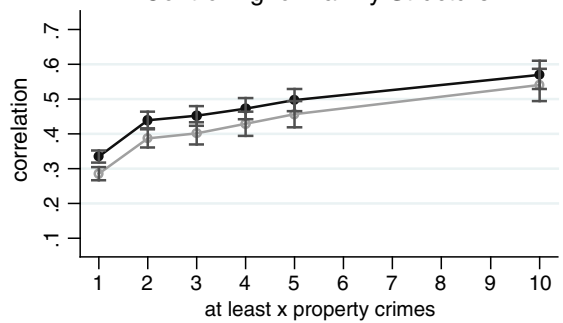

Sister correlations in property crime Controlling for All Family Background Variables

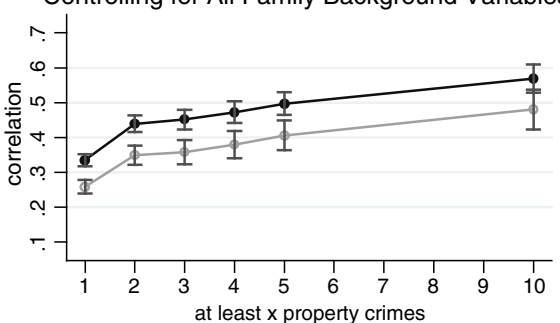

Fig. 9 Sibling correlations in property crime controlling for parental income and education, parental criminality, and family structure. Note: We show the sibling correlations estimated with (without) controls in grey (black) 
Brother correlations in violent crime Controlling for Parental Income and Education

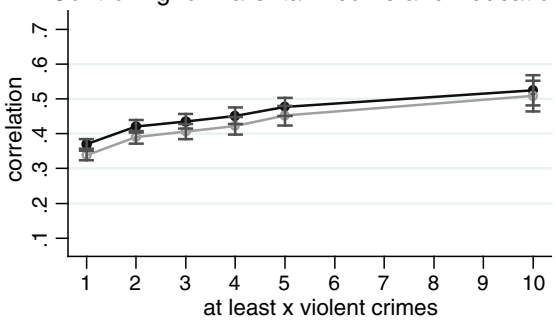

Brother correlations in violent crime Controlling for Parental Criminality

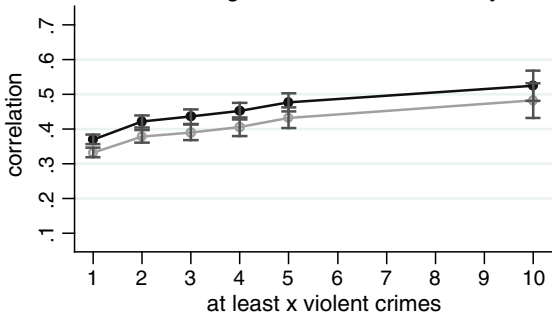

Brother correlations in violent crime Controlling for Family Structure

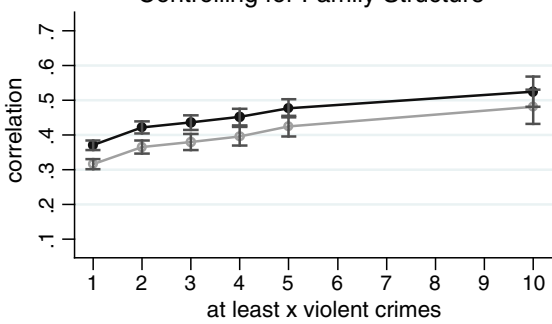

Brother correlations in violent crime Controlling for All Family Background Variables

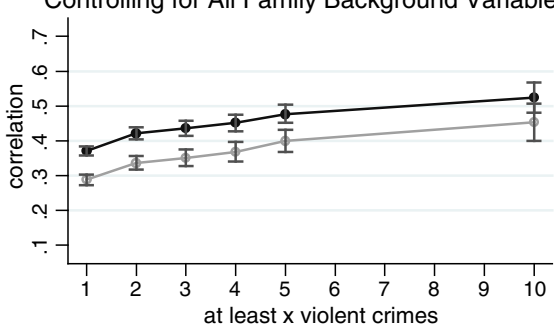

Sister correlations in violent crime Controlling for Parental Income and Education

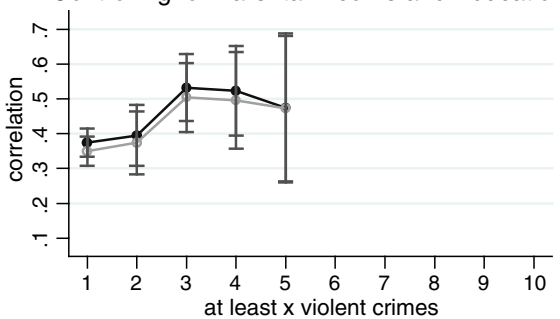

Sister correlations in violent crime Controlling for Parental Criminality

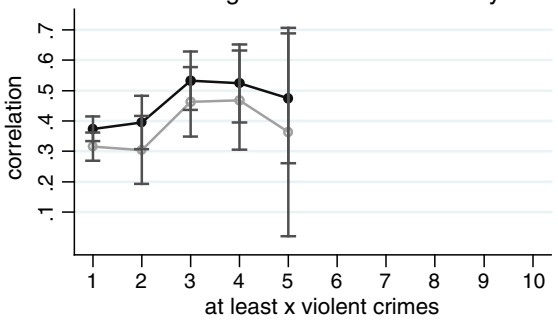

Sister correlations in violent crime Controlling for Family Structure

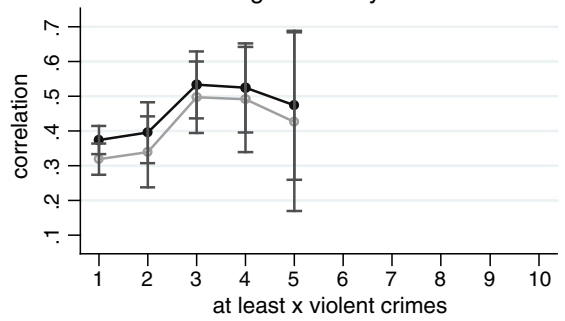

Sister correlations in violent crime Controlling for All Family Background Variables

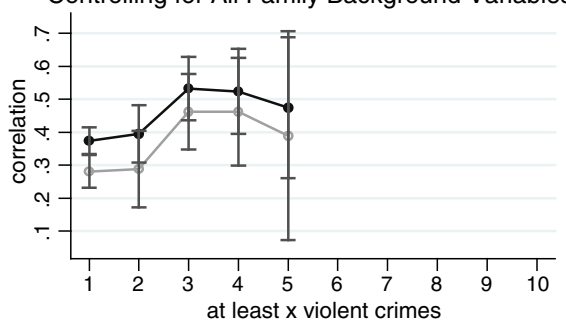

Fig. 10 Sibling correlations in violent crime controlling for parental income and education, parental criminality, and family structure. Note: We show the sibling correlations estimated with (without) controls in grey (black) 
Brother correlations in other crime Controlling for Parental Income and Education

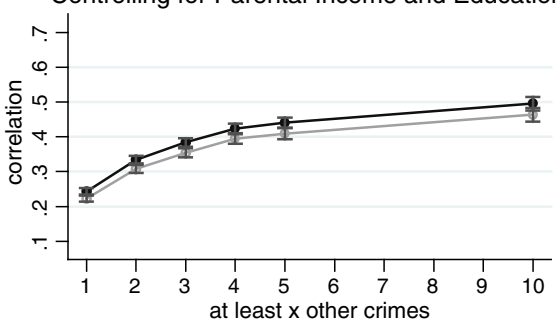

Brother correlations in other crime Controlling for Parental Criminality

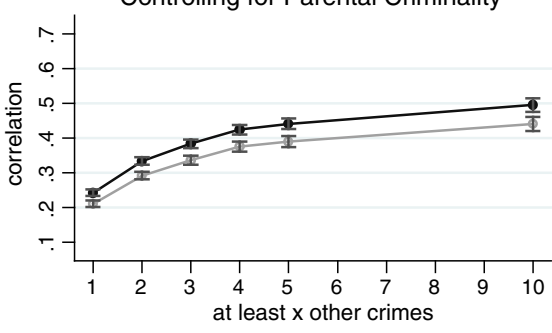

Brother correlations in other crime Controlling for Family Structure

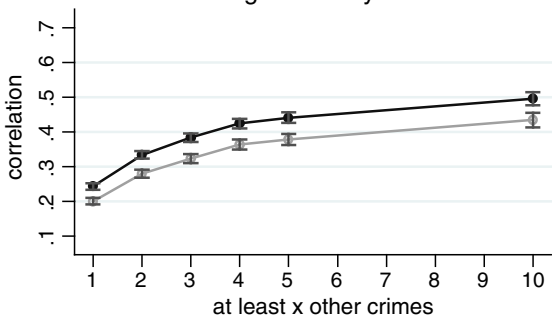

Brother correlations in other crime Controlling for All Family Background Variables

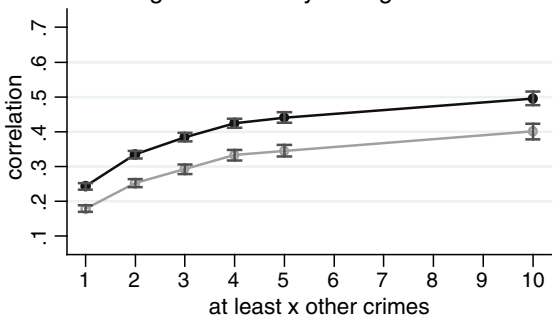

Sister correlations in other crime Controlling for Parental Income and Education

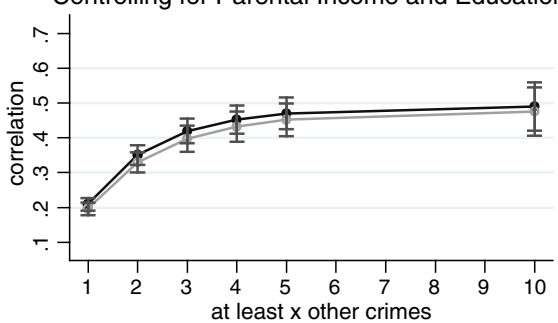

Sister correlations in other crime Controlling for Parental Criminality

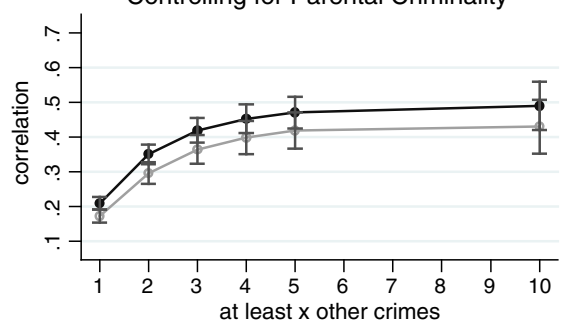

Sister correlations in other crime Controlling for Family Structure

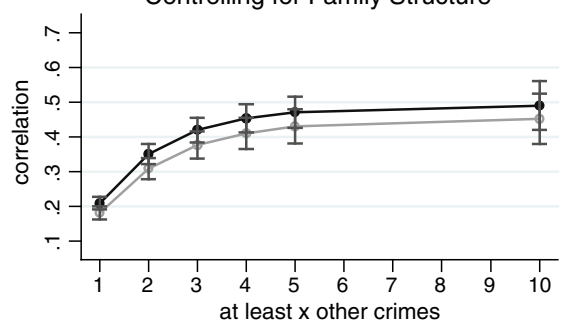

Sister correlations in other crime Controlling for All Family Background Variables

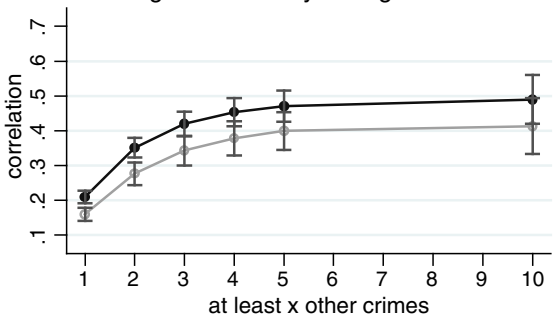

Fig. 11 Sibling correlations in other crime controlling for parental income and education, parental criminality, and family structure. Note: We show the sibling correlations estimated with (without) controls in grey (black) 


\section{References}

Åslund O, Edin PA, Grönqvist H, Fredriksson P (2011) Peers, neighborhoods, and immigrant student achievement-evidence from a placement policy. Am Econ J Appl Econ 3(2):67-95

Akee RKQ, Copeland WE, Keeler G, Angold A, Costello EJ (2010) Parents' incomes and children's outcomes: a quasi-experiment using transfer payments from casino profits. Am Econ J Appl Econ 2(1):86-115

Altonji JG, Cattan S, Ware I (2013) Identifying sibling influence on teenage substance use. IFS Working Papers W13/04

Anger S, Schnitzlein DD (2013) Like brother, like sister? - the importance of family background for cognitive and non-cognitive skills. Unpublished manuscript. DIW Berlin

Bayer P, Hjalmarsson R, Pozen D (2008) Building criminal capital behind bars: peer effects in juvenile corrections. Q J Econ 124(1):105-147

Björklund A, Lindahl L, Lindquist MJ (2010) What more than parental income, education and occupation? An exploration of what Swedish siblings get from their parents. BE J Econ Anal Poli 10(1):1-38. Contributions, Article 102

Björklund A, Jäntti M (2012) How important is family background for labor-economic outcomes? Labour Econ 19(4):465-474

Brännström L (2004) Poor places, poor prospects? Counterfactual models of neighbourhood effects on social exclusion in Stockholm. Sweden Urban Stud 41(13):2515-2537

Buhrmester D (1992) The developmental courses of sibling and peer relationships. In: Boer F, Dunn J (eds) Children's Sibling Relationships: Developmental and Clinical Issues. Hillsdale, NJ: Lawrence Erlbaum Associates

Cáceres-Delpiano J, Giolito E (2012) The impact of unilateral divorce on crime. J Labor Econ 30(1):215248

Calvó-Armengol A, Patacchini E, Zenou Y (2009) Peer effects and social networks in education. Rev Econ Stud 76(4):1239-1267

Case AC, Katz LF (1991) The company you keep: the effects of family and neighborhood on disadvantaged youths. NBER Working Papers 3705

Currie J, Tekin E (2012) Understanding the cycle: childhood maltreatment and future crime. J Hum Resour 47(2):509-549

Damm AP, Dustmann C (2014) Does growing up in a high crime neighborhood affect youth criminal behavior? Am Econ Rev 104(6):1806-32

Doyle JJ (2008) Child protection and adult crime: using investigator assignment to estimate causal effects of foster care. J Polit Econ 116(4):746-770

Edin PA, Fredriksson P, Åslund O (2003) Ethnic enclaves and the economic success of immigrants: evidence from a natural experiment. Q J Econ 118(1):329-357

Eley TC, Lichtenstein P, Moffitt TE (2013) A longitudinal behavioral genetic analysis of the etiology of aggressive and nonaggressive antisocial behavior. Dev Psychopathol 15(2):383-402

Frisell T, Lichtenstein P, Långström N (2011) Violent crime runs in families: a total population study of 12.5 million individuals. Psychol Med 41(1):97-105

Gaviria A, Raphael S (2001) School-based peer effects and juvenile behavior. Rev Econ Stat 83(2):257268

Glaze L, Maruschak L (2008) Parents in prison and their minor children. Bureau of Justice Statistics Special Report, NCJ 222984

Hjalmarsson R, Lindquist MJ (2010) Driving under the influence of our fathers. BE J Econ Anal Poli 10(1):1-15. Topics, Article 100

Hjalmarsson R, Lindquist MJ (2012) Like godfather, like son: exploring the intergenerational nature of crime. J Hum Resour 47(2):550-582

Hjalmarsson R, Lindquist MJ (2013) The origins of intergenerational associations in crime: lessons from Swedish adoption data. Labour Econ 20:68-81

Hjalmarsson R, Holmlund H, Lindquist MJ (forthcoming) The Effect of education on criminal convictions and incarceration: causal evidence from micro-data. Econ J. doi:10.1111/ecoj.12204

Holmlund H, Lindahl M, Plug E (2011) The causal effect of parents' schooling on children's schooling: a comparison of estimation methods. J Econ Lit 49(3):615-51 
Ishikawa SS, Raine A (2002) Behavioral genetics and crime. In: Glickson J (ed) The neurobiology of criminal behavior. Kluwer, Norwell, pp 81-110

Johnson RC (2007) Intergenerational risks of criminal involvement and incarceration. Goldman School of Public Policy. University of California, Berkeley

Kling JR, Ludwig J, Katz LF (2005) Neighborhood effects on crime for female and male youth: evidence from a randomized housing voucher experiment. Q J Econ 120(1):87-130

Krivo LJ, Peterson RD (1996) Extremely disadvantaged neighborhoods and urban crime. Soc Forces 75(2):619-650

Lauritsen JL (1993) Sibling resemblance in juvenile delinquency: findings from the national youth survey. Criminology 31(3):387-409

Lindahl L (2011) Does the childhood environment matter for school performance, education and income?-Evidence from a Stockholm cohort. J Econ Inequal 9(2):207-226

Lindquist MJ, Zenou Y (2014) Key players in co-offending networks. CEPR Discussion Papers DP9889

Liu X, Patacchini E, Zenou Y, Lung-Fei L (2012) Criminal networks: who is the key player? FEEM Working Paper

Lochner L, Moretti E (2004) The effect of education on crime: evidence from prison inmates, arrests and self-reports. Am Econ Rev 94(1):155-189

Ludwig J, Duncan GJ, Hirschfield P (2001) Urban poverty and juvenile crime: evidence from a randomized housing-mobility experiment. Q J Econ 116(2):655-679

Machin S, Marie O, Vujić S (2011) The crime reducing effect of education. Econ J 121:463-484

Mazumder B (2008) Sibling similarities and economic inequality in the U.S. J Popul Econ 21(3):685-701

Mazumder B (2011) Family and community influences on health and socioeconomic status: sibling correlations over the life course. BE J Econ Anal Poli 11(3):1-21. Contributions, Article 1

McPherson M., Smith-Lovin L, Cook JM (2001) Birds of a feather: Homophily in social networks. Annual Review of Sociology 27:415-44

Meghir C, Palme M, Schnabel M (2012) The effect of education policy on crime: an intergenerational perspective. NBER Working Papers 18145

Moffit TE (2005) The new look of behavioral genetics in developmental psychology: gene-environment interplay in antisocial behaviors. Psychol Bull 131(4):533-554

Needle R, McCubbin H, Wilson M, Reineck R, Lazar A, Mederer H (1986) Interpersonal influences in adolescent drug use-the role of older siblings, parents, and peers. Int J Addict 21(7):739-766

Oettinger G (2000) Sibling similarity in high school graduation outcomes: causal interdependency or unobserved heterogeneity? South Econ J 66(3):631-648

Ouyang L (2004) Sibling effects on teen risky behaviors. Unpublished paper, Department of Economics, Duke University

Pezzin LE (2004) Effects of family background on crime participation and criminal earnings: an empirical analysis of siblings. Estud Econ 34(3):487-514

Rodgers J, Rowe D. (1988) Influence of siblings on adolescent sexual behavior. Dev Psychol 24(5): $722-728$

Rowe DC, Farrington DP (1997) The familial transmission of criminal convictions. Criminology 35(1):177-201

Ruef M, Aldrich HE, Carter NM (2003) The structure of founding teams: Homophily, strong ties, and isolation among U.S. entrepreneurs. Am Sociol Rev 68(2):195-222

Sariaslan A, Långström N, D’Onofrio B, Hallqvist J, Franck J, Lichtenstein P (2013) The impact of neighborhood deprivation on adolescent violent criminality and substance misuse: a Swedish total population longitudinal quasi-experimental study. Int J Epidemiol 42(4):1057-1066

Schrøter Joensen J, Skyt Nielsen H (2015) Peer effects in math and science. Unpublished manuscript, Stockholm School of Economics

Slomkowski C, Rende R, Conger K, Simons J, Conger R (2001) Sisters, brothers, and delinquency: evaluating social inuence during early and middle adolescence. Child Dev 72(1):271-283

Solon G (1999) Intergenerational mobility in the labor market. In: Ashenfelter O, Card D (eds) Handbook of labor economics, vol 3. Elsevier, pp 1761-1800

Solon G, Page ME, Duncan GJ (2000) Correlations between neighboring children in their subsequent educational attainment. Rev Econ Stat 82(3):383-392

Winkleby M, Cubbin C, Ahn D (2006) Effect of cross-level interaction between individual and neighborhood socioeconomic status on adult mortality rates. Am J Public Health 96(12):2145-2152 